\title{
ANN Training Method with a Small Number of Examples Used for Robots Control
}

\author{
E. Ciupan, F. Lungu, C. Ciupan
}

\author{
Emilia Ciupan, Florin Lungu, Cornel Ciupan* \\ Technical University of Cluj-Napoca \\ Romania, 400641 Cluj-Napoca, Bd. Muncii, 103-105 \\ emilia.ciupan@mis.utcluj.ro, florin.lungu@mis.utcluj.ro \\ *Corresponding author: cornel.ciupan@muri.utcluj.ro
}

\begin{abstract}
This paper presents a method for obtaining a neural model used in industrial robots control. The method refers to the forming of a small number of examples used in the training of a neural network that lead to the creation of a suitable model. This paper constitutes a development of the work [2] in order to increase the opportunities for its application in various fields. The description of the method is generally done, without relying on a specific application in the domain of industrial robots. The testing and the validation of the shown method were completed using the example of a system in which the relationship between inputs and outputs is described by means of mathematical functions. The set of learning examples, generated through the proposed method, served to the ANN training by a cross-validation technique, in case of these functions. The evaluation of the proposed method has been done by analysing the results obtained by applying it compared to those obtained with a known method, namely the uniform generation of training examples. The use of the method in the field of industrial robots' control was illustrated by a concrete application in the case of a robot with 6 degrees of freedom.
\end{abstract}

Keywords: ANN, training, method, small number, robot, control.

\section{Introduction}

The control proper is achieved by the robot's control equipment by generating a control value for each joint, so that the joint achieve coordinate $q_{i}$ resulted from the inverse kinematics, and the effector move through points of coordinates that belong to the trajectory. Therefore determining the coordinates of the joints is of capital importance [7].

Neural networks can perform complex learning and adaptation tasks by imitating the function of biological neural systems, and thus can be used as models for nonlinear, multi-variable systems, trained by using input-output data observed on the system [3].

The application of neural networks to robots control is well known $[1,4,6]$ and an alternative to the adaptive control is represented by the neural controllers [8].

The models based on neural networks show an advantage in terms of model simplification and, first and foremost, of the operations performed, as they consist solely of multiplications and additions. A model based on neural networks that would answer parallel robot control involves appropriate modelling and very good network training. The large number of the training data necessary for a high-quality neural model, which can reach thousands of examples [5], can often be problematic. That is why the problem that this paper solves consists in the completion of a method for obtaining a high-quality neural network with a small number of training examples, one that grants both the desired precision in the entire robot's workspace and a reduction of the training time. Let us consider a robot with six degrees of freedom having three translation axes that give the positioning movement $\mathrm{X}, \mathrm{Y}, \mathrm{Z}$, and other three rotation axes that give the orientation movement $\psi, \theta, \varphi$. 
Based on the robot's kinematic scheme [4], there has been determined the mathematical model for the direct kinematics (1)-(2), as well as the model for inverse kinematic analysis (3)(4):

$$
\begin{gathered}
X=q_{1} \cdot i_{T x}+X_{0} ; Y=q_{2} \cdot i_{T y}+Y_{0} ; Z=q_{3} \cdot i_{T z}+Z_{0} ; \\
\psi=q_{4} \cdot i_{T \psi}+\psi_{0} ; \theta=q_{5} \cdot i_{T \theta}+\theta_{0} ; \varphi=q_{6} \cdot i_{T \varphi}+\varphi_{0} ; \\
q_{1}=\frac{X-X_{0}}{i_{T x}} ; q_{2}=\frac{Y-Y_{0}}{i_{T y}} ; q_{3}=\frac{Z-Z_{0}}{i_{T z}} ; \\
q_{4}=\frac{\psi-\psi_{0}}{i_{T \psi}} ; q_{5}=\frac{\theta-\theta_{0}}{i_{T \theta}} ; q_{6}=\frac{\varphi-\varphi_{0}}{i_{T \varphi}}
\end{gathered}
$$

where $i_{T x}, i_{T y}, i_{T z}, i_{T \psi}, i_{T \theta}, i_{T \varphi}$ represent the transfer functions of the transformation mechanisms that generate the given movements and $X_{0}, Y_{0}, Z_{0}, \psi_{0}, \theta_{0}, \varphi_{0}$ represent the values of the system origin for which $q_{i}=0, \mathrm{i}=1, \ldots, 6$.

\section{Description of the method used for the generation of training examples and its validation}

The majority of robots have six degrees of freedom and, consequently, six joints. The current paper aims at finding a method of reducing the number of training examples of a neural network for the control of a robot with six degrees of freedom. In order to describe the method, a random system with 6 input signals, and 6 output ones, is being considered. In the process of building the neural network that is to shape the system, there is used a set of training examples in which the input is represented by vectors of values $\left(q_{1}, q_{2}, q_{3}, q_{4}, q_{5}, q_{6}\right)$, where $q_{i} \in\left[q_{\min }, q_{\max }\right]$, $\forall i=\overline{1,6}$. The output values of the system are described by the values of the vectorial function $F=\left(f_{1}, f_{2}, f_{3}, f_{4}, f_{5}, f_{6}\right)$, where $\mathrm{F}:\left[q_{\min }, q_{\max }\right]^{6} \rightarrow R^{6}$

According to the method proposed, the set of training examples results from the imposition of a successive move of the signals $q_{i}, \mathrm{i}=1, \ldots, 6$, by the successive move of each signal by a step $\mathrm{p}$, followed by mixed moves of several axes, for each set $\mathrm{j}$ of input data $q_{i, j}, \mathrm{i}=1, \ldots, 6$ and $\mathrm{j}=1, \ldots, \mathrm{m}$, where $\mathrm{m}$ is the total number of sets of this type, resulting in a set of output data $F\left(q_{1 j}, q_{2 j}, q_{3 j}, q_{4 j}, q_{5 j}, q_{6 j}\right)$ that is used for the network training. The training and testing data is determined according to the mathematical model for the function $\mathrm{F}$ by modifying the input signals according to Table 1.

In the mathematical model for function $\mathrm{F}$, sets of the input signals $\left(q_{1}, q_{2}, q_{3}, q_{4}, q_{5}, q_{6}\right)$ are gradually being introduced, and the output values are calculated. The data obtained after the completion of Table 1 represents the set of training examples. The novelty of this method consists in the way used to determine the neural network training data in order to achieve a high-quality neural network by means of a small number of training examples. A high-quality neural network is defined here as a neural model that offers acceptable errors in the entire domain of function $\mathrm{F}$. In order to train the network effectively with a relatively reduced number of training examples, we suggest the use of an algorithm of generating the set of training examples which implies the completion of 30 phases expressed concisely in Table 1. A phase, denoted here by h, corresponds to a set of pairs of $\operatorname{six}\left(q_{i}, \mathrm{i}=1, \ldots, 6\right)$, one for each factor $\mathrm{z}$ of multiplication of the step $\mathrm{p}$, as it is shown explicitly in phase 1 in the Table 1 . The modification of the inputs is done based on the relation below: 
ANN Training Method with a Small Number of Examples Used

for Robots Control

\begin{tabular}{|c|c|c|c|c|c|c|c|c|c|c|c|c|}
\hline \multirow{2}{*}{$\begin{array}{c}\text { Phase } \\
\mathrm{h} \\
\end{array}$} & \multicolumn{6}{|c|}{ Input values $\left(q_{i}, \mathrm{i}=1, \ldots, 6\right)$} & \multicolumn{6}{|c|}{$\begin{array}{c}\text { Output values } \\
\mathrm{P}_{\mathrm{h} z}\left(\mathrm{f}_{1}, \mathrm{f}_{2}, \mathrm{f}_{3}, \mathrm{f}_{4}, \mathrm{f}_{\mathrm{s}}, \mathrm{f}_{6}\right), \mathrm{h}=1, \ldots, 30, \mathrm{z}=0, \ldots, \mathrm{j}\end{array}$} \\
\hline & $\mathrm{q}_{1}$ & $g_{2}$ & $q_{3}$ & $g_{4}$ & $q_{5}$ & $\mathrm{q}_{6}$ & $\mathrm{f}_{1}$ & $\mathrm{f}_{2}$ & $\mathrm{f}_{3}$ & $\mathrm{f}_{4}$ & $f_{5}$ & $f_{5}$ \\
\hline \multirow[t]{5}{*}{1.} & \multirow{5}{*}{$q_{1 \min }+z-p$} & \multirow[t]{5}{*}{$\mathrm{q}_{2 \min }$} & \multirow[t]{5}{*}{$q_{3 \min }$} & \multirow[t]{5}{*}{$\mathrm{q}_{4 \mathrm{~min}}$} & \multirow[t]{5}{*}{$\mathrm{q}_{5 \mathrm{~min}}$} & \multirow[t]{5}{*}{$\mathrm{q}_{6 \mathrm{~min}}$} & $\mathrm{fl}_{1,0}$ & $f 2_{1,0}$ & $\mathrm{f}_{1,0}$ & $\mathrm{fH}_{1,0}$ & $\mathrm{f5}_{1,0}$ & $f 6_{1,0}$ \\
\hline & & & & & & & $\ldots$ & $\ldots$ & $\ldots$ & $\ldots$ & & \\
\hline & & & & & & & $\mathrm{fl}_{1, z}$ & $f 2_{1, z}$ & $\mathrm{f}_{1, z}$ & $\mathrm{fH}_{1, z}$ & $\mathrm{f5}_{1, z}$ & $f 6_{1, z}$ \\
\hline & & & & & & & $\ldots$ & $\ldots$ & $\ldots$ & $\ldots$ & $\ldots$ & $\ldots$ \\
\hline & & & & & & & $\mathrm{fl}_{\mathrm{l}, \mathrm{i}}$ & $f 2_{1, i}$ & $\mathrm{f3}_{1, i}$ & $\mathrm{fA}_{1, \mathrm{i}}$ & $\mathrm{f5}_{1, \mathrm{i}}$ & $f 6_{1, i}$ \\
\hline 2. & $q_{1 \min }$ & $q_{2 \min }+z-p$ & $\mathrm{q}_{3 \min }$ & $\mathrm{q}_{4 \min }$ & $\mathrm{q}_{5 \min }$ & $\mathrm{q}_{6 \min }$ & $\mathrm{fl}_{2, z}$ & $\mathrm{f}_{2 ; 2 ; z}$ & $\mathrm{f3}_{2, z}$ & $f 4_{2 ; z}$ & $\mathrm{f5}_{2 ; z}$ & $f 6_{2, z}$ \\
\hline 3. & $\mathrm{q}_{1 \min }$ & $\mathrm{q}_{2 \min }$ & $q_{3 \min }+z-p$ & $\mathrm{q}_{4 \min }$ & $\mathrm{q}_{5 \min }$ & $\mathrm{q}_{6 \mathrm{~min}}$ & $\mathrm{fl}_{3, z}$ & $\mathrm{f}_{3, z}$ & $\mathrm{fB}_{3, z}$ & $\mathrm{f} 4_{3, z}$ & $\mathrm{f5}_{3, z}$ & $f 6_{3, z}$ \\
\hline 4. & $\mathrm{q}_{1 \min }$ & $q_{2 \min }$ & $q_{3 \min }$ & $q_{4 \min }+z-p$ & $\mathrm{q}_{5 \mathrm{~min}}$ & $\mathrm{q}_{6 \min }$ & $\mathrm{fl}_{4, z}$ & $\mathrm{f} 2_{4 ; z}$ & $\mathrm{f}_{4,2}$ & $\mathrm{fH}_{4 ; \mathrm{x}}$ & $\mathrm{f5}_{4, z}$ & $\mathrm{fb}_{4, z}$ \\
\hline 5. & $q_{1 \min }$ & $\mathrm{q}_{2 \min }$ & $\mathrm{q}_{3 \min }$ & $\mathrm{q}_{4 \min }$ & $q_{5 \min }+z-p$ & $\mathrm{q}_{6 \min }$ & $\mathrm{fl}_{5, z}$ & $f 2_{s, z}$ & $f 3_{S, z}$ & $f 4_{s, z}$ & $\mathrm{f5}_{5, z}$ & $f 6_{9, z}$ \\
\hline 6. & $\mathrm{q}_{1 \min }$ & $\mathrm{q}_{2 \min }$ & $\mathrm{q}_{3 \min }$ & $\mathrm{q}_{4 \min }$ & $\mathrm{q}_{5 \mathrm{~min}}$ & $q_{6 \text { min }}+z-p$ & $\mathrm{fl}_{6 ; z}$ & $f 2_{6 ; z}$ & $\mathrm{f3}_{6 ; z}$ & $f 4_{6 ; z}$ & f5 $_{6, z}$ & $\mathrm{fb}_{6 ; z}$ \\
\hline 7. & $q_{1 \min }+z-p$ & $\mathrm{q}_{2 \mathrm{med}}$ & $q_{3} \mathrm{mad}$ & $\mathrm{q}_{4 \mathrm{med}}$ & $\mathrm{q}_{5 \mathrm{med}}$ & $q_{6 m e d}$ & $\mathrm{fl}_{7, z}$ & $f 2_{7 ; z}$ & $\mathrm{f3}_{7, z}$ & $\mathrm{f} 4_{7, z}$ & $\mathrm{f5}_{7, \boldsymbol{z}}$ & $f 6_{7, z}$ \\
\hline 8. & $\mathrm{q}_{\text {lmed }}$ & $\mathrm{g}_{2 \min }+\mathrm{z} \cdot \mathrm{p}$ & $\mathrm{q}_{3}$ med & $\mathrm{q}_{4 \mathrm{med}}$ & $\mathrm{q}_{5 \mathrm{med}}$ & $\mathrm{q}_{6 \mathrm{med}}$ & $\mathrm{fl}_{8 ; z}$ & $f 2_{s ; z}$ & $\mathrm{f}_{3, z}$ & $\mathrm{f} 4_{\mathrm{s} ; \mathrm{z}}$ & $\mathrm{f5}_{\mathrm{s}, \mathrm{z}}$ & $f 6_{9, z}$ \\
\hline 9. & $\mathrm{q}_{\text {lmed }}$ & $q_{2 m e d}$ & $\mathrm{~g}_{3 \min }+\mathrm{z} \cdot \mathrm{p}$ & $\mathrm{q}_{4 \mathrm{med}}$ & $\mathrm{q}_{\mathrm{s} \text { med }}$ & $\mathrm{q}_{6 \mathrm{med}}$ & $\mathrm{fl}_{9 ; z}$ & $f 2_{9, z}$ & $\mathrm{f}_{9 ; z}$ & $\mathrm{f} 4_{9, z}$ & $\mathrm{f5}_{9, z}$ & $f 6_{9, z}$ \\
\hline 10. & qlmed & $\mathrm{q}_{2 \mathrm{med}}$ & $\mathrm{q}_{3 \mathrm{med}}$ & $\mathrm{q}_{4 \min }+\mathrm{z} \cdot \mathrm{p}$ & $\mathrm{q}_{5 \mathrm{med}}$ & $\mathrm{q}_{6 \mathrm{med}}$ & $\mathrm{fl}_{10 ; z}$ & $f 2_{10 ; z}$ & $\mathrm{f}_{10 ; z}$ & $\mathrm{fA}_{10 ; z}$ & $\mathrm{f5}_{10 ; z}$ & $\mathrm{f6}_{10 ; z}$ \\
\hline 11. & $\mathrm{q}_{1 \mathrm{med}}$ & $\mathrm{q}_{2 \mathrm{mad}}$ & $\mathrm{q}_{3 \mathrm{med}}$ & $\mathrm{q}_{4 \mathrm{med}}$ & $\mathrm{q}_{5 \min }+\mathrm{z} \cdot \mathrm{p}$ & $\mathrm{q}_{6 \mathrm{med}}$ & $\mathrm{fl}_{11, z}$ & $\mathrm{f} 2_{11, x}$ & $\mathrm{f3}_{11 ; x}$ & $f 4_{11, z}$ & $\mathrm{f5}_{11, z}$ & $f 6_{11, z}$ \\
\hline 12. & $q_{l m e d}$ & $\mathrm{q}_{2 \mathrm{med}}$ & $\mathrm{q}_{3 \mathrm{med}}$ & $\mathrm{q}_{4 \mathrm{med}}$ & $\mathrm{q}_{5 \mathrm{med}}$ & $q_{6 \min }+z-p$ & $\mathrm{fl}_{12 ; z}$ & $\mathrm{f}_{212, z}$ & $\mathrm{f3}_{12 ; 2}$ & $f 4_{12, x}$ & $\mathrm{f5}_{12 ; x}$ & $f 6_{12, x}$ \\
\hline 13. & $q_{1 \min }+z-p$ & $\mathrm{q}_{2 \max }$ & $\mathrm{q}_{3 \max }$ & $\mathrm{q}_{4 \max }$ & $\mathrm{q}_{5_{\max }}$ & $q_{6 \max }$ & $\mathrm{fl}_{13, z}$ & $\mathrm{f} 2_{13, x}$ & $\mathrm{fB}_{13 ; 2}$ & $\mathrm{f} 4_{13, x}$ & $\mathrm{fS}_{13, x}$ & $f 6_{13, z}$ \\
\hline 14. & $\mathrm{q}_{1 \max }$ & $q_{2 \min }+z-p$ & $q_{3 \max }$ & $\mathrm{q}_{4 \max }$ & $q_{5 \max }$ & $q_{6 \max }$ & $\mathrm{fl}_{14, z}$ & $f 2_{14 ; x}$ & $\mathrm{f3}_{14, z}$ & $\mathrm{f} 4_{14, z}$ & $\mathrm{f5}_{14 ; z}$ & $f 6_{14 ; z}$ \\
\hline 15. & $\mathrm{q}_{\operatorname{lmax}}$ & $q_{2 \max }$ & $q_{3 \min }+z-p$ & $\mathrm{q}_{4 \max }$ & $\mathrm{q}_{5 \max }$ & $q_{6 \max }$ & $\mathrm{fl}_{15, z}$ & $\mathrm{f}_{15, z}$ & $\mathrm{f}_{15, z}$ & $\mathrm{fH}_{15, x}$ & $\mathrm{f5}_{15, x}$ & $f 6_{15, z}$ \\
\hline 16. & $q_{1 \max }$ & $\mathrm{q}_{2 \max }$ & $\mathrm{q}_{3 \max }$ & $q_{4 \min }+z-p$ & $\mathrm{q}_{s_{\max }}$ & $\mathrm{q}_{6 \max }$ & $\mathrm{fl}_{16, z}$ & $f 2_{16, z}$ & $\mathrm{f}_{16, z}$ & $\mathrm{fA}_{16, z}$ & $\mathrm{f5}_{16 ; z}$ & $\mathrm{fb}_{16: \mathrm{x}}$ \\
\hline 17. & $\mathrm{q}_{\operatorname{lmax}}$ & $\mathrm{q}_{2 \max }$ & $q_{3 \max }$ & $\mathrm{q}_{4 \max }$ & $q_{5 \min }+z-p$ & $\mathrm{q}_{6 \max }$ & $\mathrm{fl}_{17, z}$ & $\mathrm{f} 2_{17, z}$ & $\mathrm{fB}_{17, z}$ & $\mathrm{f} 4_{17, x}$ & $\mathrm{fS}_{17, x}$ & $f 6_{17, z}$ \\
\hline 18. & $\mathrm{q}_{\operatorname{lmax}}$ & $\mathrm{q}_{2 \max }$ & $\mathrm{q}_{3 \max }$ & $\mathrm{q}_{4 \max }$ & $\mathrm{q}_{5 \max }$ & $q_{6 \min }+z-p$ & $\mathrm{fl}_{18, z}$ & $\mathrm{f}_{2} 18, z$ & $\mathrm{f}_{18, z}$ & $\mathrm{f}_{18, z}$ & $\mathrm{f5}_{18, z}$ & $f 6_{18, z}$ \\
\hline 19. & $q_{1 \text { min }}+z-p$ & $q_{2 \min }+z-p$ & $\mathrm{q}_{3 \mathrm{med}}$ & $\mathrm{q}_{4 \mathrm{med}}$ & $\mathrm{q}_{5 \mathrm{med}}$ & $\mathrm{q}_{6 \mathrm{med}}$ & $\mathrm{fl}_{19, z}$ & $f 2_{19, z}$ & $\mathrm{f}_{19 ; z}$ & $\mathrm{fH}_{19, z}$ & $\mathrm{f5}_{19 ; z}$ & $\mathrm{fb}_{19, z}$ \\
\hline 20. & $\mathrm{q}_{1 \mathrm{mad}}$ & $q_{2 \text { mad }}$ & $q_{3 \min }+z-p$ & $q_{4 \min }+z-p$ & $\mathrm{q}_{5 \mathrm{mad}}$ & $\mathrm{q}_{6 \mathrm{mad}}$ & $\mathrm{fl}_{20, z}$ & $\mathrm{f}_{20 ; x}$ & $\mathrm{fB}_{20 ; x}$ & $\mathrm{fH}_{20 ; x}$ & $\mathrm{f5}_{20, z}$ & $f 6_{20, z}$ \\
\hline 21. & $\mathrm{q}_{\text {lmad }}$ & $\mathrm{q}_{2 \mathrm{mad}}$ & $q_{3} \mathrm{med}$ & $\mathrm{q}_{4} \mathrm{med}$ & $q_{5 \min }+z-p$ & $q_{6 \min }+z-p$ & $\mathrm{fl}_{21, \boldsymbol{z}}$ & $\mathrm{f}_{21, z}$ & $\mathrm{fB}_{21, x}$ & $\mathrm{fH}_{21, z}$ & $\mathrm{f5}_{21, z}$ & $f 6_{21 ; z}$ \\
\hline 22. & $q_{1 \min }+z-p$ & $q_{2 \min }+z-p$ & $q_{3 \min }+z-p$ & $\mathrm{q}_{4 \mathrm{mad}}$ & $\mathrm{q}_{5 \mathrm{mad}}$ & $q_{6 m e d}$ & $\mathrm{fl}_{22, x}$ & $\mathrm{f}_{22, x}$ & $\mathrm{fB}_{2 n, x}$ & $\mathrm{fH}_{22, x}$ & $\mathrm{f5}_{2 n, z}$ & $f 6_{22 ; z}$ \\
\hline 23. & $\mathrm{q}_{1 \mathrm{mad}}$ & $q_{2 \text { mad }}$ & $\mathrm{q}_{3 \mathrm{mad}}$ & $q_{4 \min }+z-p$ & $q_{5 \min }+z-p$ & $q_{6 \min }+z-p$ & $\mathrm{fl}_{23, x}$ & $\mathrm{f}_{23, x}$ & $\mathrm{f}_{23, x}$ & $\mathrm{fA}_{23, z}$ & $\mathrm{f5}_{23, z}$ & $f 6_{23, x}$ \\
\hline 24. & $q_{1 \min }+z-p$ & $q_{2 \min }+z-p$ & $q_{3 \min }+z-p$ & $q_{4 \min }+z-p$ & $\mathrm{q}_{5 \mathrm{mad}}$ & $\mathrm{q}_{6 \mathrm{med}}$ & $\mathrm{fl}_{24, z}$ & $\mathrm{f}_{24, z}$ & $\mathrm{fB}_{24, z}$ & $\mathrm{f} 4_{24, z}$ & $\mathrm{f5}_{24, z}$ & $\mathrm{fb}_{24 ; z}$ \\
\hline 25. & $\mathrm{q}_{1 \mathrm{med}}$ & $q_{2 m a d}$ & $q_{3 \min }+z \cdot p$ & $q_{4 \min }+z-p$ & $q_{5 \min }+z-p$ & $q_{6 \min }+z-p$ & $\mathrm{fl}_{25, x}$ & $\mathrm{f}_{25, x}$ & $\mathrm{f}_{25, x}$ & $\mathrm{fH}_{25, z}$ & $\mathrm{f5}_{25, z}$ & $f 6_{25 ; z}$ \\
\hline 26. & $q_{1 \min }+z-p$ & $q_{2 \min }+z-p$ & $q_{3 \min }+z-p$ & $q_{4 \min }+z-p$ & $q_{5 \min }+z-p$ & $q_{6 \min }+z-p$ & $\mathrm{fl}_{26: z}$ & $\mathrm{f}_{26: z}$ & $\mathrm{f}_{26: z}$ & $\mathrm{fH}_{26: z}$ & $\mathrm{f5}_{26 ; z}$ & $f 6_{26: z}$ \\
\hline 27. & $q_{1 \text { min }}+z-p$ & $\mathrm{q}_{2 \min }$ & $q_{3 \min }+z-p$ & $\mathrm{q}_{4 \min }$ & $q_{5 \min }+z-p$ & $\mathrm{q}_{6 \mathrm{~min}}$ & $\mathrm{fl}_{27, z}$ & $\mathrm{f} 2_{27, x}$ & $\mathrm{f}_{27, x}$ & $\mathrm{fH}_{27, z}$ & $\mathrm{f5}_{27, z}$ & $f 6_{27, z}$ \\
\hline 28. & $q_{1 \min }+z-p$ & $q_{2 \max }$ & $q_{3 \min }+z-p$ & $\mathrm{q}_{4 \max }$ & $q_{5 \min }+z-p$ & $\mathrm{q}_{6 \max }$ & $\mathrm{fl}_{28, z}$ & $f 2_{28, x}$ & $\mathrm{f3}_{28, x}$ & $\mathrm{fH}_{28, z}$ & $\mathrm{fJ}_{28: z}$ & $f 6_{28: z}$ \\
\hline 29. & $\mathrm{q}_{1 \min }$ & $q_{2 \min }+z-p$ & $q_{3 \min }$ & $q_{4 \min }+z-p$ & $q_{5 \min }$ & $q_{6 \min }+z-p$ & $\mathrm{fl}_{29, z}$ & $\mathrm{f}_{2} 29, x$ & $\mathrm{f}_{39 ; x}$ & $\mathrm{f} 4_{2, \pi}$ & $\mathrm{fJ}_{29, z}$ & $f 6_{29, z}$ \\
\hline 30. & $\mathrm{q}_{\operatorname{lmax}}$ & $q_{2 \min }+z-p$ & $q_{3 \max }$ & $q_{4 \min }+z-p$ & $\mathrm{q}_{5 \max }$ & $q_{6 \text { min }}+z-p$ & $\mathrm{fl}_{30: x}$ & $\mathrm{f}_{30 ; x}$ & $\mathrm{f}_{30: x}$ & $\mathrm{fH}_{30 ; z}$ & $\mathrm{f5}_{30 ; z}$ & $\mathrm{fb}_{30: z}$ \\
\hline
\end{tabular}

Table 1: Generation of training examples 


$$
q_{i}=q_{\text {imin }}+z \cdot p ;
$$

where $\mathrm{z}=0, \ldots, \mathrm{j}$ for all the 30 phases, except phases $2-6$, where $\mathrm{z}=1, \ldots, \mathrm{j}$ and $\mathrm{p}$ represents the increase step given by the relation:

$$
p=\frac{q_{\text {imax }}-q_{\text {imin }}}{j} ;
$$

and $\mathrm{j}$ is the number of steps. For the validation of the method, there has been considered the example in which the input signals $q_{i} \in[0,90], \forall i=\overline{1,6}$, the step $\mathrm{p}=5$, and the components of the vectorial function $\mathrm{F}$ are defined by the following equations:

$$
\begin{gathered}
f_{1}\left(q_{1}, q_{2}, q_{3}, q_{4}, q_{5}, q_{6}\right)=10 \cdot \sin q_{1} \\
f_{2}\left(q_{1}, q_{2}, q_{3}, q_{4}, q_{5}, q_{6}\right)=10 \cdot\left(1-\cos q_{2}\right) \\
f_{3}\left(q_{1}, q_{2}, q_{3}, q_{4}, q_{5}, q_{6}\right)=\frac{10}{q_{\max }^{2}} \cdot q_{3}^{2} \\
f_{4}\left(q_{1}, q_{2}, q_{3}, q_{4}, q_{5}, q_{6}\right)=\frac{q_{4}}{9} \\
f_{5}\left(q_{1}, q_{2}, q_{3}, q_{4}, q_{5}, q_{6}\right)=\frac{q_{5}}{9} \\
f_{6}\left(q_{1}, q_{2}, q_{3}, q_{4}, q_{5}, q_{6}\right)=\frac{q_{6}}{9}
\end{gathered}
$$

According to the rule described concisely in Table 1, there has been generated a set of training data of the neural network formed by pairs of examples $\left(\left(q_{1}, q_{2}, q_{3}, q_{4}, q_{5}, q_{6}\right), F\left(q_{1}, q_{2}, q_{3}, q_{4}, q_{5}, q_{6}\right)\right)$. After the elimination of the repeated values, there has been obtained a set of 382 examples, marked as trainProp. In order to compare the method proposed with the known method, there has been generated the set trainKnown, with a number of elements (375) close to that of the set trainProp. The training examples of this set have been obtained by means of the same approach as in the case of the robots inverse kinematic analysis. The starting point was made of uniformely distributed values (step 3.3) in the image of function $\mathrm{F}$, respectively $[0,10]^{6}$. The values of the corresponding input signals $q_{i}, \mathrm{i}=1, \ldots, 6$ has been determined by means of the inverses of the functions $f_{1}, \ldots, f_{6}$. Table 2 illustrates the two sets, trainProp and trainKnown.

In the case of both sets, there has been applied the technique 4-fold cross-validation for the random division of each initial set of training examples into four subsets $s$ SetProp $_{l}$, and $s$ SetKnown,$l=\overline{1,4}$, respectively. The subsets of each set have been used, in a combination of three, to the training of the network, while the fourth subset has been used for the validation of the model throughout the training process. We mark the neural models obtained as a result of the instruction as netProp $k$ and netKnown,$k=\overline{1,4}$, respectively. The errors obtained in the training process are close in the case of the two methods used, and they are of order $10^{-7}$. In order to test the netProp $k$ and netKnown $k$ models, $\mathrm{k}=\overline{1,4}$, there has been constituted the set of input-output data rendered in Table 3.

The data in Table 4 show better results in the cases in which, for the training stage, there has been used the set obtained by means of the method proposed, as compared to the set achieved by means of the method known. More detailed data concerning the individual errors of the output signals are comprised in the tables 5 and 6 , both in the case of the method proposed, and in that of the method known. The variations of the absolute errors of the output signals $f_{1}, f_{2}$ and $f_{3}$ are shown in the graphs that belong to Table 5 , while those of the signals $f_{4}, f_{5}$ and $f_{6}$, are captured in the graphs corresponding to Table 6.

It can be noticed the lesser size order of the individual errors in the case of the network training by means of data obtained through the method proposed, as compared to the one known. 


\begin{tabular}{|c|c|c|c|c|c|c|c|c|c|c|c|c|c|c|c|c|c|c|c|c|c|c|c|c|c|}
\hline \multicolumn{13}{|c|}{ Proposed method } & \multicolumn{13}{|c|}{ Known method } \\
\hline \multirow[t]{2}{*}{ No. } & \multicolumn{6}{|c|}{$\begin{array}{l}\text { Input values } \\
\left(q_{i}, \mathrm{i}=1, \ldots, 6\right)\end{array}$} & \multicolumn{6}{|c|}{$\begin{array}{l}\text { Output values } \\
F\left(q_{i}, i=1, \ldots, 6\right)\end{array}$} & \multirow[t]{2}{*}{ No. } & \multicolumn{6}{|c|}{$\begin{array}{l}\text { Input values } \\
\left(q_{i}, \mathrm{i}=1, \ldots, 6\right)\end{array}$} & \multicolumn{6}{|c|}{$\begin{array}{l}\text { Output values } \\
F(q i, i=1, \ldots, 6)\end{array}$} \\
\hline & $\mathrm{q} 1$ & $\mathrm{q} 2$ & $q^{3}$ & $q 4$ & q5 & $q 6$ & $\mathrm{f} 1$ & $\mathrm{f} 2$ & f3 & $\mathrm{f4}$ & f5 & f6 & & $\mathrm{q} 1$ & q2 & $q^{3}$ & q4 & q5 & $q 6$ & $\mathrm{f} 1$ & $\mathrm{f} 2$ & $\mathrm{f} 3$ & $\mathrm{f4}$ & f5 & f6 \\
\hline 1 & 0 & 0 & 0 & 0 & 0 & 0 & 0.00 & 0 & 0 & 0 & 0 & 0 & 1 & 0.00 & 47.93 & 51.70 & 29.70 & 29.70 & 29.70 & 0 & 3.3 & 3.3 & 3.3 & 3.3 & 3.3 \\
\hline 2 & 5 & 0 & 0 & 0 & 0 & 0 & 0.87 & 0 & 0 & 0 & 0 & 0 & 2 & 19.27 & 47.93 & 51.70 & 29.70 & 29.70 & 29.70 & \begin{tabular}{|l|} 
\\
\end{tabular} & 3.3 & 3.3 & 3.3 & 3.3 & 3.3 \\
\hline 3 & 10 & 0 & 0 & 0 & 0 & 0 & 1.74 & 0 & 0 & 0 & 0 & 0 & 3 & 41.30 & 47.93 & 51.70 & 29.70 & 29.70 & 29.70 & \begin{tabular}{|l|}
6.6 \\
\end{tabular} & 3.3 & 3.3 & 3.3 & 3.3 & 3.3 \\
\hline 4 & 15 & 0 & 0 & 0 & 0 & 0 & 2.59 & 0 & 0 & 0 & 0 & 0 & 4 & 90.00 & 47.93 & 51.70 & 29.70 & 29.70 & 29.70 & 10 & 3.3 & 3.3 & 3.3 & 3.3 & 3.3 \\
\hline 5 & 20 & 0 & 0 & 0 & 0 & 0 & 3.42 & 0 & 0 & 0 & 0 & 0 & 5 & 19.27 & 0.00 & 51.70 & 29.70 & 29.70 & 29.70 & \begin{tabular}{|l|} 
\\
\end{tabular} & 0 & 3.3 & 3.3 & 3.3 & 3.3 \\
\hline 6 & 25 & 0 & 0 & 0 & 0 & 0 & 4.23 & 0 & 0 & 0 & 0 & 0 & 6 & 19.27 & 70.12 & 51.70 & 29.70 & 29.70 & 29.70 & 3.3 & 6.6 & 3.3 & 3.3 & 3.3 & 3.3 \\
\hline 7 & 30 & 0 & 0 & 0 & 0 & 0 & 5.00 & 0 & 0 & 0 & 0 & 0 & 7 & 19.27 & 90.00 & 51.70 & 29.70 & 29.70 & 29.70 & 3.3 & 10 & 3.3 & 3.3 & 3.3 & 3.3 \\
\hline 8 & 35 & 0 & 0 & 0 & 0 & 0 & 5.74 & 0 & 0 & 0 & 0 & 0 & 8 & 19.27 & 47.93 & \begin{tabular}{|l|}
0.00 \\
\end{tabular} & 29.70 & 29.70 & 29.70 & \begin{tabular}{|l|}
3.3 \\
\end{tabular} & 3.3 & 0 & 3.3 & 3.3 & 3.3 \\
\hline 9 & 40 & 0 & 0 & 0 & 0 & 0 & 6.43 & 0 & 0 & 0 & 0 & 0 & 9 & 19.27 & 47.93 & 73.12 & 29.70 & 29.70 & 29.70 & \begin{tabular}{|l|}
3.3 \\
\end{tabular} & 3.3 & 6.6 & 3.3 & 3.3 & 3.3 \\
\hline 10 & 45 & 0 & 0 & 0 & 0 & 0 & 7.07 & 0 & 0 & 0 & 0 & 0 & 10 & 19.27 & 47.93 & 90.00 & 29.70 & 29.70 & 29.70 & 3.3 & 3.3 & 10 & 3.3 & 3.3 & 3.3 \\
\hline 11 & 50 & 0 & 0 & 0 & 0 & 0 & 7.66 & 0 & 0 & 0 & 0 & 0 & 11 & 19.27 & 47.93 & 51.70 & 0.00 & 29.70 & 29.70 & \begin{tabular}{|l|}
3.3 \\
\end{tabular} & 3.3 & 3.3 & 0 & 3.3 & 3.3 \\
\hline 12 & 55 & 0 & 0 & 0 & 0 & 0 & 8.19 & 0 & 0 & 0 & 0 & 0 & 12 & 19.27 & 47.93 & 51.70 & 59.40 & 29.70 & 29.70 & 3.3 & 3.3 & 3.3 & 6.6 & 3.3 & 3.3 \\
\hline 13 & 60 & 0 & 0 & 0 & 0 & 0 & 8.66 & 0 & 0 & 0 & 0 & 0 & 13 & 19.27 & 47.93 & 51.70 & 90.00 & 29.70 & 29.70 & 3.3 & 3.3 & 3.3 & 10 & 3.3 & 3.3 \\
\hline 14 & 65 & 0 & 0 & 0 & 0 & 0 & 9.06 & 0 & 0 & 0 & 0 & 0 & 14 & 19.27 & 47.93 & 51.70 & 29.70 & 0.00 & 29.70 & \begin{tabular}{|l|} 
\\
\end{tabular} & 3.3 & 3.3 & 3.3 & 0 & 3.3 \\
\hline 15 & 70 & 0 & 0 & 0 & 0 & 0 & 9.40 & 0 & 0 & 0 & 0 & 0 & 15 & 19.27 & 47.93 & 51.70 & 29.70 & 59.40 & 29.70 & \begin{tabular}{|l|}
3.3 \\
\end{tabular} & 3.3 & 3.3 & 3.3 & 6.6 & 3.3 \\
\hline 16 & 75 & 0 & 0 & 0 & 0 & 0 & 9.66 & 0 & 0 & 0 & 0 & 0 & 16 & 19.27 & 47.93 & 51.70 & 29.70 & 90.00 & 29.70 & 3.3 & 3.3 & 3.3 & 3.3 & 10 & 3.3 \\
\hline 17 & 80 & 0 & 0 & 0 & 0 & 0 & 9.85 & 0 & 0 & 0 & 0 & 0 & 17 & 19.27 & 47.93 & 51.70 & 29.70 & 29.70 & \begin{tabular}{|l|l|} 
\\
\end{tabular} & 3.3 & 3.3 & 3.3 & 3.3 & 3.3 & 0 \\
\hline 18 & 85 & 0 & 0 & 0 & 0 & 0 & 9.96 & 0 & 0 & 0 & 0 & 0 & 18 & 19.27 & 47.93 & 51.70 & 29.70 & 29.70 & 59.40 & \begin{tabular}{|l|}
3.3 \\
\end{tabular} & 3.3 & 3.3 & 3.3 & 3.3 & 6.6 \\
\hline 19 & 90 & 0 & 0 & 0 & 0 & 0 & 10 & 0 & 0 & 0 & 0 & 0 & 19 & 19.27 & 47.93 & 51.70 & 29.70 & 29.70 & 90.00 & 3.3 & 3.3 & 3.3 & 3.3 & 3.3 & 10 \\
\hline$\ldots$ & & & & & & & & & & & & & $\ldots$ & & & & & & & & & & & & \\
\hline 365 & 90 & 5 & 90 & 5 & 90 & 5 & 10 & 0.04 & 10 & 0.56 & 10 & 0.56 & 358 & $\mid 19.27$ & 90.00 & 90.00 & 90.00 & 90.00 & 90.00 & 3.3 & 10 & 10 & 10 & 10 & 10 \\
\hline 366 & 90 & 10 & 90 & 10 & 90 & 10 & 10 & 0.15 & 10 & \begin{tabular}{|l|}
1.11 \\
\end{tabular} & \begin{tabular}{|l|}
10 \\
\end{tabular} & 1.11 & 359 & 41.30 & 90.00 & \begin{tabular}{|l|}
90.00 \\
\end{tabular} & \begin{tabular}{|l|}
90.00 \\
\end{tabular} & \begin{tabular}{|l|}
90.00 \\
\end{tabular} & 90.00 & 6.6 & 10 & 10 & 10 & 10 & 10 \\
\hline 367 & 90 & 15 & 90 & 15 & 90 & 15 & 10 & 0.34 & 10 & 1.67 & \begin{tabular}{|l|}
10 \\
\end{tabular} & 1.67 & 360 & 90.00 & 0.00 & 90.00 & 90.00 & 90.00 & 90.00 & 10 & 0 & 10 & 10 & 10 & 10 \\
\hline 368 & 90 & 20 & 90 & 20 & 90 & 20 & 10 & 0.60 & 10 & 2.22 & 10 & 2.22 & 361 & 90.00 & 47.93 & 90.00 & 90.00 & \begin{tabular}{|l|}
90.00 \\
\end{tabular} & 90.00 & 10 & 3.3 & 10 & 10 & 10 & 10 \\
\hline 369 & 90 & 25 & 90 & 25 & 90 & 25 & 10 & 0.94 & 10 & 2.78 & 10 & 2.78 & 362 & 90.00 & 70.12 & 90.00 & 90.00 & 90.00 & 90.00 & 10 & 6.6 & 10 & 10 & 10 & 10 \\
\hline 370 & 90 & 30 & 90 & 30 & 90 & 30 & 10 & 1.34 & 10 & \begin{tabular}{|l|l|}
3.33 \\
\end{tabular} & 10 & 3.33 & 363 & 90.00 & 90.00 & \begin{tabular}{|l|}
0.00 \\
\end{tabular} & \begin{tabular}{|l|}
90.00 \\
\end{tabular} & \begin{tabular}{|l|}
90.00 \\
\end{tabular} & 90.00 & 10 & 10 & 0 & 10 & 10 & 10 \\
\hline 371 & 90 & 35 & 90 & 35 & 90 & 35 & 10 & 1.81 & 10 & \begin{tabular}{|l|}
3.89 \\
\end{tabular} & 10 & 3.89 & 364 & 90.00 & 90.00 & 51.70 & 90.00 & \begin{tabular}{|l|}
90.00 \\
\end{tabular} & 90.00 & 10 & 10 & 3.3 & 10 & 10 & 10 \\
\hline 372 & 90 & 40 & 90 & 40 & 90 & 40 & 10 & 2.34 & 10 & 4.44 & 10 & 4.44 & 365 & 90.00 & 90.00 & 73.12 & 90.00 & 90.00 & 90.00 & 10 & 10 & 6.6 & 10 & 10 & 10 \\
\hline 373 & 90 & 45 & 90 & 45 & 90 & 45 & 10 & 2.93 & 10 & 5.00 & 10 & 5.00 & 366 & 90.00 & 90.00 & 90.00 & 0.00 & 90.00 & 90.00 & 10 & 10 & 10 & 0 & 10 & 10 \\
\hline 374 & 90 & 50 & 90 & 50 & 90 & 50 & 10 & 3.57 & 10 & 5.56 & \begin{tabular}{|l|}
10 \\
\end{tabular} & 5.56 & 367 & 90.00 & 90.00 & \begin{tabular}{|l|}
90.00 \\
\end{tabular} & \begin{tabular}{|l|}
29.70 \\
\end{tabular} & 90.00 & 90.00 & 10 & 10 & 10 & 3.3 & 10 & 10 \\
\hline 375 & 90 & 55 & 90 & 55 & 90 & 55 & 10 & 4.26 & 10 & \begin{tabular}{|l|}
6.11 \\
\end{tabular} & \begin{tabular}{|l|}
10 \\
\end{tabular} & 6.11 & 368 & 90.00 & 90.00 & 90.00 & \begin{tabular}{|l|}
59.40 \\
\end{tabular} & \begin{tabular}{|l|}
90.00 \\
\end{tabular} & 90.00 & 10 & 10 & 10 & 6.6 & 10 & 10 \\
\hline 376 & 90 & 60 & 90 & 60 & 90 & 60 & 10 & 5.00 & 10 & \begin{tabular}{|l|}
6.67 \\
\end{tabular} & 10 & 6.67 & 369 & 90.00 & 90.00 & 90.00 & 90.00 & \begin{tabular}{|l|l|}
0.00 \\
\end{tabular} & 90.00 & 10 & 10 & 10 & 10 & 0 & 10 \\
\hline 377 & 90 & 65 & 90 & 65 & 90 & 65 & 10 & 5.77 & 10 & 7.22 & 10 & 7.22 & 370 & 90.00 & 90.00 & 90.00 & 90.00 & 29.70 & 90.00 & 10 & 10 & 10 & 10 & 3.3 & 10 \\
\hline 378 & 90 & 70 & 90 & 70 & 90 & 70 & 10 & 6.58 & 10 & \begin{tabular}{|l|l|} 
\\
\end{tabular} & 10 & 7.78 & 371 & 90.00 & 90.00 & 90.00 & 90.00 & 59.40 & 90.00 & 10 & 10 & 10 & 10 & 6.6 & 10 \\
\hline 379 & 90 & 75 & 90 & 75 & 90 & 75 & 10 & 7.41 & 10 & 8.33 & 10 & 8.33 & 372 & 90.00 & 90.00 & 90.00 & 90.00 & 90.00 & 0.00 & 10 & 10 & 10 & 10 & 10 & 0 \\
\hline 380 & 90 & 80 & 90 & 80 & 90 & 80 & 10 & 8.26 & 10 & \begin{tabular}{|l|}
8.89 \\
\end{tabular} & 10 & 8.89 & 373 & 90.00 & 90.00 & 90.00 & 90.00 & \begin{tabular}{|l|}
90.00 \\
\end{tabular} & 29.70 & 10 & 10 & 10 & 10 & 10 & 3.3 \\
\hline 381 & 90 & 85 & 90 & 85 & 90 & 85 & 10 & 9.13 & 10 & \begin{tabular}{|l|}
9.44 \\
\end{tabular} & \begin{tabular}{|l|}
10 \\
\end{tabular} & 9.44 & 374 & 90.00 & 90.00 & \begin{tabular}{|l|}
90.00 \\
\end{tabular} & \begin{tabular}{|l|}
90.00 \\
\end{tabular} & 90.00 & 59.40 & 10 & 10 & 10 & 10 & 10 & 6.6 \\
\hline 382 & 90 & 90 & 90 & 90 & 90 & 90 & 10 & 10 & 10 & 10 & 10 & 10 & 375 & 90.00 & 90.00 & 90.00 & 90.00 & 90.00 & 90.00 & 10 & 10 & 10 & 10 & 10 & 10 \\
\hline
\end{tabular}

Table 2: Training data generation

\begin{tabular}{|r|r|r|r|r|r|r|r|r|r|r|r|r|}
\hline \multirow{2}{*}{ No } & \multicolumn{7}{|c|}{ Inputs } & \multicolumn{6}{|c|}{ Outputs } \\
\cline { 2 - 14 } & q1 & q2 & q3 & q4 & q5 & q6 & f1 & f2 & f3 & f4 & f5 & f6 \\
\hline 1 & 0.5 & 0.5 & 0.5 & 0.5 & 0.5 & 0.5 & 0.087265 & 0.000381 & 0.000309 & 0.055556 & 0.0555556 & 0.055556 \\
\hline 2 & 1.5 & 1.5 & 1.5 & 1.5 & 1.5 & 1.5 & 0.261769 & 0.003427 & 0.002778 & 0.166667 & 0.166667 & 0.166667 \\
\hline 3 & 2.5 & 2.5 & 2.5 & 2.5 & 2.5 & 2.5 & 0.436194 & 0.009518 & 0.007716 & 0.277778 & 0.277778 & 0.277778 \\
\hline 4 & 3.5 & 3.5 & 3.5 & 3.5 & 3.5 & 3.5 & 0.610485 & 0.018652 & 0.015123 & 0.388889 & 0.388889 & 0.388889 \\
\hline 5 & 4.5 & 4.5 & 4.5 & 4.5 & 4.5 & 4.5 & 0.784591 & 0.030827 & 0.025 & 0.5 & 0.5 & 0.5 \\
\hline$\ldots$ & & & & & & & & & & & & 9.5 \\
\hline 86 & 85.5 & 85.5 & 85.5 & 85.5 & 85.5 & 85.5 & 9.969173 & 9.215409 & 9.025 & 9.5 & 9.5 & 9.5 \\
\hline 87 & 86.5 & 86.5 & 86.5 & 86.5 & 86.5 & 86.5 & 9.981348 & 9.389515 & 9.237346 & 9.611111 & 9.611111 & 9.611111 \\
\hline 88 & 87.5 & 87.5 & 87.5 & 87.5 & 87.5 & 87.5 & 9.990482 & 9.563806 & 9.45216 & 9.722222 & 9.722222 & 9.722222 \\
\hline 89 & 88.5 & 88.5 & 88.5 & 88.5 & 88.5 & 88.5 & 9.996573 & 9.738231 & 9.669444 & 9.833333 & 9.833333 & 9.833333 \\
\hline 90 & 89.5 & 89.5 & 89.5 & 89.5 & 89.5 & 89.5 & 9.999619 & 9.912735 & 9.889198 & 9.944444 & 9.944444 & 9.944444 \\
\hline
\end{tabular}

Table 3: Testing data 


\begin{tabular}{|c|c|c|}
\hline \multirow{2}{*}{ k } & \multicolumn{2}{|c|}{ Mean square error } \\
\hline & netProp $_{k}$ & netKnown $_{k}$ \\
\hline 1 & $2.25 \mathrm{E}-04$ & 8.37E-02 \\
\hline 2 & $1.83 \mathrm{E}-04$ & $8.34 \mathrm{E}-02$ \\
\hline 3 & 2.39E-04 & $8.45 \mathrm{E}-02$ \\
\hline 4 & $1.93 \mathrm{E}-04$ & $7.88 \mathrm{E}-02$ \\
\hline
\end{tabular}

Table 4: Testing results

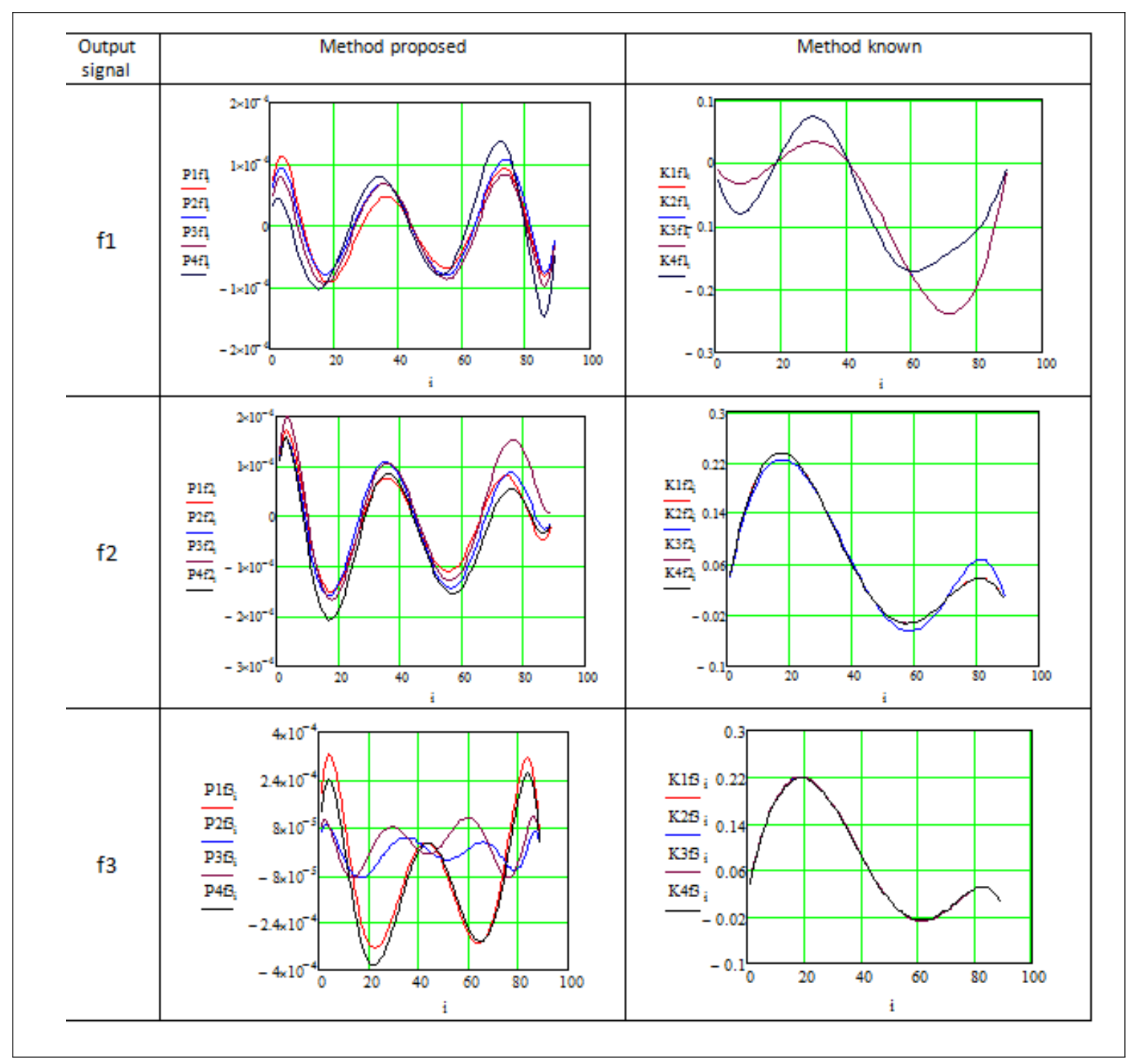

Table 5: The error variation in the case of the signals $f_{1}, f_{2}, f_{3}$ 


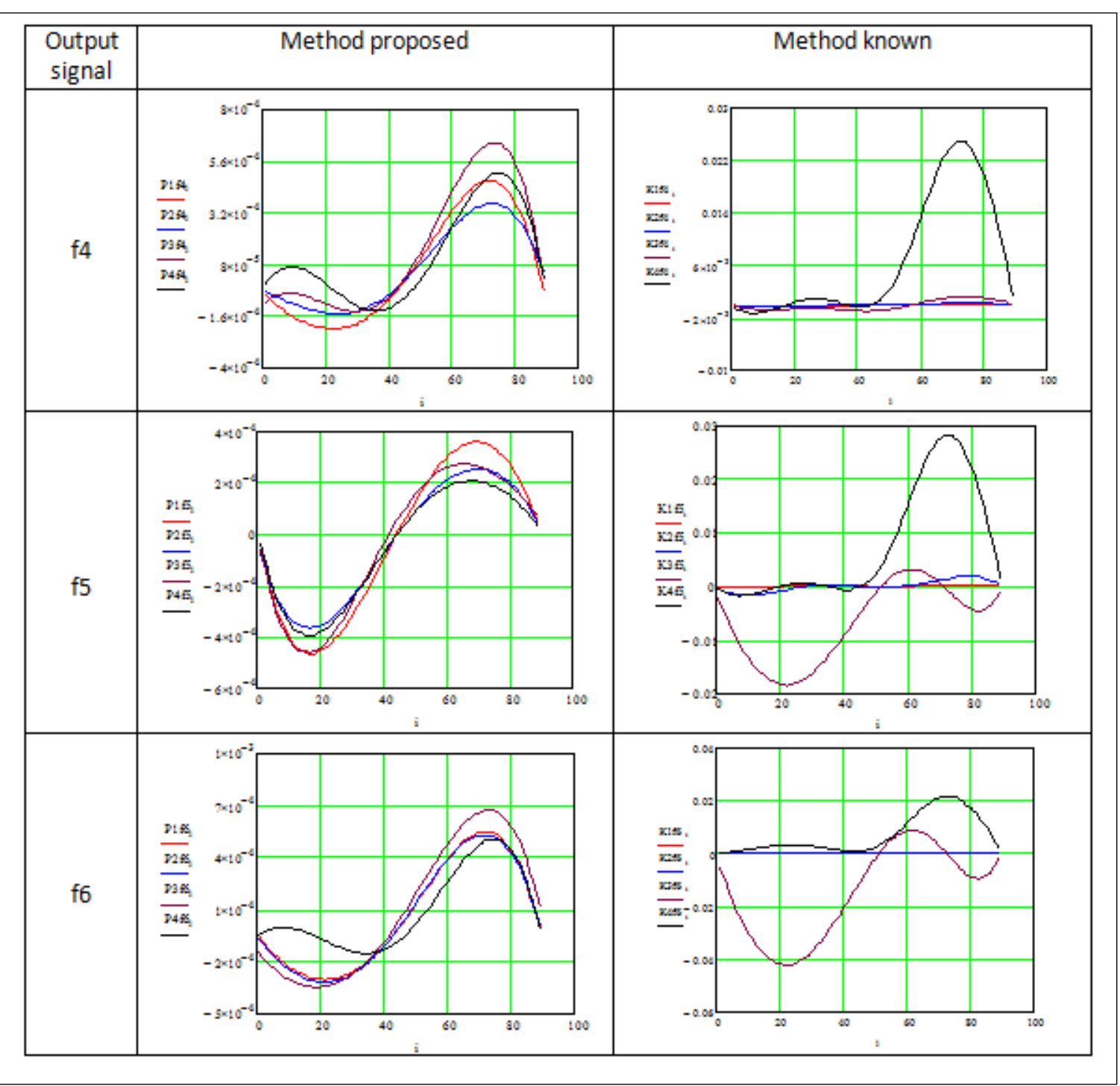

Table 6: The error variation in the case of the signals $f_{4}, f_{5}, f_{6}$ 


\section{Application for a robot with 6 degrees of freedom}

Let us consider the robots workspace as a cube with the side of $300 \mathrm{~mm}$. Based on the algorithm shown in Table 1, there will be generated three sets of training examples for the method proposed here, taking into account in the model for direct kinematic analysis (1)-(2) the following constants:

$$
\begin{gathered}
i_{T x}=i_{T y}=i_{T z}=10 ; i_{T \psi}=i_{T \theta}=i_{T \varphi}=3 ; \\
X_{0}=0 ; Y_{0}=0 ; Z_{0}=300 ; \psi_{0}=\theta_{0}=\varphi_{0}=-60^{\circ} ;
\end{gathered}
$$

The above value of $-60^{\circ}$ for the angular variables was chosen so that the coordinates of the joints differs from 0 in the system reference point.

In order to validate the method suggested here, an alternative is considered to be the method of formation the training examples by the evenly distributed choice of the coordinates of the effector in the robot's workspace. For the method known, of evenly distributed choice of the coordinates, there will be generated three sets of data. The training data is obtained from the model for inverse kinematic analysis (3)-(4) with initial values from relation (13)-(14). In order to generate each set of training data (Set 1, Set 2, Set 3) corresponding to the two methods,

\begin{tabular}{|c|c|c|c|c|c|c|c|c|}
\hline \multicolumn{2}{|c|}{ Data set } & \multirow{2}{*}{$\frac{\mathrm{q}_{1}}{20}$} & \multirow{2}{*}{$\frac{\mathrm{q}_{2}}{20}$} & \multirow{2}{*}{$\frac{\mathrm{q}_{3}}{20}$} & \multirow{2}{*}{$\begin{array}{l}\mathrm{q}_{4} \\
20\end{array}$} & \multirow{2}{*}{$\begin{array}{l}\mathrm{q}_{5} \\
20\end{array}$} & \multirow{2}{*}{$\begin{array}{l}q_{6} \\
20\end{array}$} & \multirow{2}{*}{\begin{tabular}{|c}
$\begin{array}{c}\text { No. of } \\
\text { examples }\end{array}$ \\
$\mathrm{n}$ \\
\end{tabular}} \\
\hline \multirow{4}{*}{ Set 1} & $q_{\text {imin }}$ & & & & & & & \\
\hline & $q_{\text {imax }}$ & 50 & 50 & 50 & 50 & 50 & 50 & \multirow{3}{*}{$\mathrm{n}=104$} \\
\hline & $p$ & 10 & 10 & 10 & 10 & 10 & 10 & \\
\hline & $\mathrm{j}$ & 3 & 3 & 3 & 3 & 3 & 3 & \\
\hline \multirow{4}{*}{ Set 2} & $q_{\text {imin }}$ & 20 & 20 & 20 & 20 & 20 & 20 & \multirow{4}{*}{$\mathrm{n}=194$} \\
\hline & $\mathrm{q}_{\mathrm{imax}}$ & 50 & 50 & 50 & 50 & 50 & 50 & \\
\hline & $\mathrm{p}$ & 5 & 5 & 5 & 5 & 5 & 5 & \\
\hline & j & 6 & 6 & 6 & 6 & 6 & 6 & \\
\hline \multirow{7}{*}{ Set 3} & $\mathrm{q}_{\mathrm{i} \text { min }}$ & 20 & 20 & 20 & 20 & 20 & 20 & \multirow{7}{*}{$\mathrm{n}=448$} \\
\hline & $\mathrm{q}_{\mathrm{imax}}$ & 50 & 50 & 50 & 50 & 50 & 50 & \\
\hline & $p$ & 2 & 2 & 2 & 2 & 2 & 2 & \\
\hline & $j$ & 15 & 15 & 15 & 15 & 15 & 15 & \\
\hline & & $x$ & $Y$ & z & $\psi$ & $\theta$ & $\varphi$ & \\
\hline & $\min$ & 200 & 200 & 200 & 0 & 0 & 0 & \\
\hline & $\max$ & 500 & 500 & 500 & 90 & 90 & 90 & \\
\hline
\end{tabular}
there has been used the data in Table 7 .

\begin{tabular}{|c|c|c|c|c|c|c|c|}
\hline \multirow[t]{2}{*}{ Data set } & \multirow[t]{2}{*}{$\mathrm{x}$} & \multirow[t]{2}{*}{$\mathrm{Y}$} & \multirow[t]{2}{*}{ Z } & \multirow[t]{2}{*}{$\psi$} & \multirow[t]{2}{*}{$\theta$} & \multirow[t]{2}{*}{$\varphi$} & $\begin{array}{c}\text { No. of } \\
\text { examples }\end{array}$ \\
\hline & & & & & & & $\mathrm{n}$ \\
\hline \multirow{4}{*}{ Set 1} & & & & 0 & 0 & 0 & \multirow{4}{*}{$\mathrm{n}=3 \times 3 \times 3 \times 4=10$} \\
\hline & 200 & 200 & 500 & 90 & 0 & 0 & \\
\hline & 350 & 350 & 650 & 0 & 90 & 0 & \\
\hline & 500 & 500 & 800 & 0 & 0 & 90 & \\
\hline \multirow{4}{*}{ Set 2} & 200 & 200 & 200 & 0 & 0 & 0 & \multirow{4}{*}{$\mathrm{n}=4 \mathrm{x} 4 \mathrm{x} 4 \mathrm{x} 4=256$} \\
\hline & 300 & 300 & 300 & 90 & 0 & 0 & \\
\hline & 400 & 400 & 400 & 0 & 90 & 0 & \\
\hline & 500 & 500 & 500 & 0 & 0 & 90 & \\
\hline \multirow{7}{*}{ Set 3} & & & & 0 & 0 & 0 & \multirow{7}{*}{$\mathrm{n}=4 \mathrm{x} 4 \mathrm{x} 4 \mathrm{x} 6=448$} \\
\hline & 200 & 200 & 500 & 45 & 0 & 0 & \\
\hline & 300 & 300 & 600 & 0 & 45 & 0 & \\
\hline & 400 & 400 & 700 & 0 & 0 & 45 & \\
\hline & \multirow[t]{3}{*}{500} & \multirow[t]{3}{*}{500} & \multirow[t]{3}{*}{800} & 90 & 0 & 0 & \\
\hline & & & & 0 & 90 & 0 & \\
\hline & & & & 0 & 0 & 90 & \\
\hline
\end{tabular}

Table 7: Training data sets

The number of a set's training examples was denoted by $\mathrm{n}$ and it acquired different values in the case of each set. Using the data in Tables 1 and 7 there has been generated for each method a set of training data. In order to make a comparison between the results of the two methods, there have been used sets of data having the cardinality of the set of training examples (n) close (Set 1, Set 2) or identical (Set 3).

Table 8 shows in parallel the set of training data for the proposed method, and Set 1 for the known method. There has been modelled a three-layer neural network (6-20-6) and the training with the three sets of data resulted in three neural models for each method. For each set of data and for each method, there have been obtained close errors of training $\left(e<10^{-5}\right)$. In order to compare the two methods, the neural networks have been tested for each set and method. For the comparison of the results, there has been taken into account the move of the effector in the robot's workspace on a diagonal between the coordinate points $P_{1}(210,210,670)$ and $P_{2}(490$, $490,790)$. For the orientation of the effector, there has been considered a rotation $\varphi=90^{\circ}$. The values of the input signals are shown in columns 1-6 in Table 9. The positioning error in Table 9 represents the resultant of the positioning coordinates error (X, Y, Z). Similarly, the angular error represents the resultant of the angular errors $(\psi, \theta, \varphi)$. Table 10 shows graphically the 
ANN Training Method with a Small Number of Examples Used

for Robots Control

\begin{tabular}{|c|c|c|c|c|c|c|c|c|c|c|c|c|c|c|c|c|c|c|c|c|c|c|c|c|c|c|}
\hline \multicolumn{14}{|c|}{ Proposed method } & \multicolumn{13}{|c|}{ Known method } \\
\hline No. & Stage & \multicolumn{6}{|c|}{$\begin{array}{l}\text { Joints coordinates } \\
\left\{q_{;}, \ldots=1, \ldots, 6 ; n=1, \ldots, 104\right)\end{array}$} & \multicolumn{6}{|c|}{$\begin{array}{l}\text { Effector coordinates } \\
\text { P. }(X, Y, Z, \Psi, \theta, \emptyset], n=1, \ldots, 104\end{array}$} & Stage & \multicolumn{6}{|c|}{$\begin{array}{l}\text { Joints coordinates } \\
\left(q_{i, \ldots}, i=1, \ldots, 6 ; n=1, \ldots, 108\right)\end{array}$} & \multicolumn{6}{|c|}{$\begin{array}{l}\text { Effector coordinates } \\
\text { P. }(X, Y, Z, \Psi, \theta, \varphi), n=1, \ldots, 108\end{array}$} \\
\hline t & $f$ & $q_{1}$ & $q_{z}$ & q, & $q_{1}$ & qs & qs & $x$ & $Y$ & $z$ & $\varphi$ & $\theta$ & $\varphi$ & $f$ & & & & 9.1 & & & $x$ & \begin{tabular}{l|}
$\mathrm{Y}$ \\
\end{tabular} & \begin{tabular}{|l|}
$z$ \\
\end{tabular} & $\psi$ & $\theta$ & \\
\hline 1 & & \begin{tabular}{|l|}
20 \\
\end{tabular} & 20 & \begin{tabular}{|l|}
20 \\
\end{tabular} & 20 & 20 & 20 & 200 & 200 & 50 & 0 & 0 & 0 & 1 & $\frac{10}{20}$ & $\frac{40}{20}$ & & $\frac{49}{20}$ & 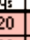 & $\frac{96}{20}$ & 200 & \begin{tabular}{|l|}
200 \\
\end{tabular} & \begin{tabular}{|l|}
5000 \\
\end{tabular} & 0 & 0 & $\frac{1}{0}$ \\
\hline 2 & 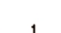 & \begin{tabular}{|l|}
30 \\
\end{tabular} & 20 & 20 & 20 & 20 & 20 & 300 & 200 & \begin{tabular}{|l|l|}
500 \\
\end{tabular} & 0 & 0 & 0 & 2 & 35 & 20 & 20 & 20 & 20 & 20 & 350 & \begin{tabular}{|l|l|}
200 \\
\end{tabular} & \begin{tabular}{|l|l|}
500 \\
\end{tabular} & 0 & 0 & 0 \\
\hline 3 & 1 & \begin{tabular}{|l|}
40 \\
\end{tabular} & 20 & 20 & 20 & 20 & 20 & 400 & \begin{tabular}{|l|l|}
200 \\
\end{tabular} & 500 & 0 & 0 & 0 & 3 & 50 & 20 & 20 & 20 & 20 & 20 & 500 & \begin{tabular}{|l|l|}
200 \\
\end{tabular} & 5000 & 0 & 0 & 0 \\
\hline 4 & & \begin{tabular}{|l|}
50 \\
\end{tabular} & 20 & 20 & 20 & 20 & 20 & 500 & 200 & \begin{tabular}{|l|}
500 \\
\end{tabular} & 0 & 0 & 0 & 4 & 20 & \begin{tabular}{l|}
35 \\
\end{tabular} & 20 & 20 & 20 & 20 & 200 & \begin{tabular}{|l|}
350 \\
\end{tabular} & \begin{tabular}{|l|l|}
500 \\
\end{tabular} & 0 & 0 & 0 \\
\hline 5 & & 20 & 30 & 20 & 20 & 20 & 20 & 200 & \begin{tabular}{|l|}
300 \\
\end{tabular} & \begin{tabular}{|l|}
500 \\
\end{tabular} & 0 & 0 & 0 & 5 & $\begin{array}{l}35 \\
5\end{array}$ & $\begin{array}{l}35 \\
5\end{array}$ & 20 & \begin{tabular}{l|l}
20 \\
20
\end{tabular} & 80 & 20 & 350 & \begin{tabular}{|l|}
350 \\
\end{tabular} & 500 & 0 & 0 & 0 \\
\hline 6 & 2 & \begin{tabular}{|l|}
20 \\
\end{tabular} & 40 & \begin{tabular}{|l|}
20 \\
\end{tabular} & 20 & 20 & 20 & 200 & \begin{tabular}{|l|l|}
400 \\
\end{tabular} & \begin{tabular}{|c|}
500 \\
\end{tabular} & 0 & 0 & 0 & $\begin{array}{ll}6 \\
7\end{array}$ & 50 & \begin{tabular}{|l|}
35 \\
\end{tabular} & 20 & 20 & 80 & 20 & 500 & \begin{tabular}{|l|}
350 \\
\end{tabular} & \begin{tabular}{|l|l}
500 \\
\end{tabular} & 0 & 0 & 0 \\
\hline$\frac{6}{7}$ & & \begin{tabular}{|l|}
20 \\
\end{tabular} & \begin{tabular}{|l|l|}
50 \\
5
\end{tabular} & 20 & 20 & 20 & 20 & 200 & \begin{tabular}{|l|}
500 \\
\end{tabular} & \begin{tabular}{|l|}
500 \\
\end{tabular} & 0 & 0 & 0 & 7 & 20 & \begin{tabular}{|l|l}
50 \\
\end{tabular} & 20 & \begin{tabular}{l|l}
20 \\
2
\end{tabular} & 80 & 20 & 200 & \begin{tabular}{|l|}
500 \\
5
\end{tabular} & \begin{tabular}{|l|l|}
500 \\
\end{tabular} & 0 & 0 & 0 \\
\hline & $\ldots$ & & & & & & & & & & & & & 8 & $\begin{array}{l}335 \\
550\end{array}$ & \begin{tabular}{|l|l|}
50 \\
50
\end{tabular} & 20 & \begin{tabular}{l|l}
20 \\
20
\end{tabular} & & $\frac{20}{20}$ & $\begin{array}{l}350 \\
500 \\
500\end{array}$ & \begin{tabular}{|l|}
500 \\
500
\end{tabular} & \begin{tabular}{|l|}
500 \\
500
\end{tabular} & 0 & 0 & 0 \\
\hline 17 & & \begin{tabular}{|l|}
20 \\
\end{tabular} & 20 & 20 & 20 & 20 & 30 & 200 & 200 & 500 & 0 & 0 & 30 & $\frac{9}{10}$ & $\frac{50}{20}$ & & $\frac{20}{35}$ & & & $\frac{20}{20}$ & $\frac{500}{200}$ & \begin{tabular}{|l|}
500 \\
200
\end{tabular} & \begin{tabular}{|l|}
500 \\
650
\end{tabular} & 0 & $\frac{0}{0}$ & $\frac{0}{0}$ \\
\hline 18 & 6 & \begin{tabular}{|l|}
20 \\
\end{tabular} & 20 & & 20 & \begin{tabular}{|l|}
20 \\
\end{tabular} & & 200 & 200 & \begin{tabular}{|l|l|}
500 \\
\end{tabular} & 0 & 0 & 60 & $\ldots$ & 20 & 201 & 35 & 20 & & & & & & & & \\
\hline 19 & & \begin{tabular}{|l|}
20 \\
\end{tabular} & 20 & \begin{tabular}{|l|}
20 \\
\end{tabular} & 20 & 20 & & 200 & 200 & \begin{tabular}{|l|l|}
500 \\
\end{tabular} & 0 & 0 & 90 & 19 & 20 & 20 & 50 & $20 \mid$ & & & 200 & 200 & 800 & 0 & 0 & 0 \\
\hline 20 & & 20 & 35 & 35 & 35 & 35 & \begin{tabular}{|l|}
35 \\
\end{tabular} & 200 & 350 & 650 & 45 & 45 & 45 & 20 & $\frac{20}{35}$ & $\frac{20}{20}$ & $\begin{array}{l}50 \\
50\end{array}$ & \begin{tabular}{l|l}
20 \\
20
\end{tabular} & $\frac{20}{20}$ & $\frac{20}{20}$ & 200 & $\frac{200}{200}$ & $\frac{800}{800}$ & 0 & 0 & 0 \\
\hline 21 & 7 & \begin{tabular}{|l|}
30 \\
\end{tabular} & 35 & 35 & 35 & 35 & 35 & 300 & 3500 & 650 & 45 & 45 & 45 & $\frac{20}{21}$ & $\begin{array}{l}355 \\
550\end{array}$ & $\frac{20}{20}$ & $\frac{50}{50}$ & $\frac{20}{20}$ & & $\frac{20}{20}$ & $\frac{350}{500}$ & 200 & 800 & 0 & 0 & 0 \\
\hline 22 & $r$ & \begin{tabular}{|l|}
40 \\
\end{tabular} & 35 & 35 & 35 & 35 & 35 & 400 & \begin{tabular}{|l|l|}
350 \\
\end{tabular} & 650 & 45 & 45 & 45 & $\frac{21}{22}$ & $\frac{50}{20}$ & $\begin{array}{l}20 \\
35\end{array}$ & $\begin{array}{l}\frac{50}{50} \\
50\end{array}$ & \begin{tabular}{c|c}
20 \\
20
\end{tabular} & & $\frac{20}{20}$ & $\frac{500}{200}$ & $\frac{200}{350}$ & 8800 & 0 & 0 & 0 \\
\hline 23 & & \begin{tabular}{|l|}
50 \\
\end{tabular} & 35 & \begin{tabular}{|l|l}
35 \\
\end{tabular} & 35 & 35 & 35 & 500 & 3500 & 650 & 45 & 45 & 45 & $\frac{22}{23}$ & $\frac{20}{35}$ & \begin{tabular}{|c|c|c|c|}
35 &
\end{tabular} & $\begin{array}{l}\frac{50}{50} \\
50\end{array}$ & \begin{tabular}{l|l}
20 \\
20
\end{tabular} & $\frac{0}{20}$ & $\frac{20}{20}$ & $\frac{200}{350}$ & $\frac{350}{350}$ & $\frac{800}{800}$ & $\frac{0}{0}$ & $\frac{0}{0}$ & 0 \\
\hline & $\cdots$ & & & & & & & & & & & & & & \begin{tabular}{|l}
50 \\
50
\end{tabular} & 35 & 50 & 20 & & & & & 8000 & & & \\
\hline 40 & & \begin{tabular}{|l|}
35 \\
\end{tabular} & 35 & 35 & 35 & 35 & 20 & 350 & 350 & 650 & 45 & 45 & 0 & $\frac{24}{25}$ & $\frac{50}{200}$ & $\begin{array}{l}35 \\
50\end{array}$ & $\begin{array}{l}50 \\
50\end{array}$ & $\frac{20}{20}$ & 0 & $\frac{20}{20}$ & $\frac{500}{200}$ & $\frac{350}{500}$ & 8000 & $\frac{0}{0}$ & 0 & 0 \\
\hline 41 & & \begin{tabular}{|l|}
35 \\
\end{tabular} & 35 & 35 & 35 & 35 & 30 & 350 & 350 & 650 & 45 & 45 & 30 & 25 & 20 & $\begin{array}{l}50 \\
50\end{array}$ & $\begin{array}{l}50 \\
50\end{array}$ & $\frac{20}{20}$ & & $\frac{20}{20}$ & 200 & $\frac{500}{500}$ & $\frac{800}{800}$ & $\frac{0}{0}$ & 0 & 0 \\
\hline $\begin{array}{l}41 \\
42\end{array}$ & 12 & \begin{tabular}{|l|}
35 \\
\end{tabular} & 35 & \begin{tabular}{|l|}
35 \\
\end{tabular} & 35 & \begin{tabular}{|l|}
35 \\
\end{tabular} & 40 & 350 & \begin{tabular}{|l|l|}
350 \\
\end{tabular} & 650 & 45 & 45 & 60 & $\begin{array}{l}26 \\
27\end{array}$ & $\begin{array}{l}355 \\
50\end{array}$ & $\begin{array}{l}50 \\
50\end{array}$ & \begin{tabular}{l|l}
50 \\
50
\end{tabular} & \begin{tabular}{l|l}
20 \\
20
\end{tabular} & $\frac{20}{20}$ & $\frac{20}{20}$ & $\begin{array}{l}350 \\
500\end{array}$ & \begin{tabular}{|l|}
500 \\
5000
\end{tabular} & \begin{tabular}{|l|l|}
8000 \\
800
\end{tabular} & $\frac{0}{0}$ & $\frac{0}{0}$ & $\frac{0}{0}$ \\
\hline 43 & & \begin{tabular}{|l|}
35 \\
\end{tabular} & 35 & 35 & 35 & 35 & 50 & 350 & \begin{tabular}{|l|l|}
350 \\
\end{tabular} & 650 & 45 & 45 & 90 & $\frac{21}{28}$ & $\frac{50}{20}$ & $\frac{50}{20}$ & $\frac{50}{20}$ & \begin{tabular}{l|l}
20 \\
50
\end{tabular} & & $\frac{20}{20}$ & $\frac{500}{200}$ & \begin{tabular}{|l|}
500 \\
200
\end{tabular} & \begin{tabular}{|l|l|}
8000 \\
500
\end{tabular} & $\frac{0}{90}$ & $\frac{0}{0}$ & 0 \\
\hline $\begin{array}{l}45 \\
44\end{array}$ & & \begin{tabular}{|l|l}
20 \\
\end{tabular} & 50 & \begin{tabular}{|l|}
50 \\
\end{tabular} & 50 & \begin{tabular}{|l|}
50 \\
\end{tabular} & 50 & 2000 & \begin{tabular}{|l|l|}
5000 \\
\end{tabular} & 800 & 90 & 90 & 90 & $\frac{28}{29}$ & $\begin{array}{l}20 \\
35\end{array}$ & $20 \mid$ & $\frac{20}{20}$ & \begin{tabular}{l|l}
50 \\
50
\end{tabular} & 20 & $\frac{20}{20}$ & $\begin{array}{l}200 \\
350\end{array}$ & \begin{tabular}{|l|}
2000 \\
200
\end{tabular} & \begin{tabular}{|l|}
500 \\
500 \\
\end{tabular} & $\frac{90}{90}$ & $\frac{0}{0}$ & $\frac{0}{0}$ \\
\hline 45 & 13 & \begin{tabular}{|l|}
30 \\
\end{tabular} & 50 & 50 & 50 & 50 & 50 & 300 & \begin{tabular}{|l|}
500 \\
\end{tabular} & 800 & 90 & 90 & 90 & 29 & $\frac{30}{50}$ & $\frac{20}{20}$ & $\frac{20}{20}$ & $\begin{array}{l}50 \\
50\end{array}$ & & $\frac{20}{20}$ & $\frac{350}{500}$ & \begin{tabular}{|l|}
2000 \\
2000
\end{tabular} & \begin{tabular}{|l|}
500 \\
500
\end{tabular} & 90 & $\frac{0}{0}$ & 0 \\
\hline 46 & & \begin{tabular}{|l|}
40 \\
\end{tabular} & 50 & \begin{tabular}{|l|}
50 \\
\end{tabular} & \begin{tabular}{|l|}
50 \\
\end{tabular} & 50 & 50 & 400 & \begin{tabular}{|l|}
500 \\
\end{tabular} & \begin{tabular}{|l|l|}
800 \\
\end{tabular} & 90 & 90 & 90 & & 50 & 20 & & 50 & & & & 200 & & & & \\
\hline 60 & & 50 & 50 & \begin{tabular}{|l|}
50 \\
\end{tabular} & 50 & \begin{tabular}{|l|}
50 \\
\end{tabular} & 20 & 500 & \begin{tabular}{|l|}
500 \\
\end{tabular} & \begin{tabular}{|l|l|}
800 \\
\end{tabular} & 90 & 90 & 0 & $\frac{31}{51}$ & 50 & 35 & 50 & \begin{tabular}{l|l}
50 \\
\end{tabular} & 0 & 20 & 500 & 350 & 800 & 90 & 0 & 0 \\
\hline 61 & 18 & 50 & 50 & \begin{tabular}{|l|}
50 \\
\end{tabular} & 50 & \begin{tabular}{|l|}
50 \\
\end{tabular} & 30 & 500 & \begin{tabular}{|l|}
500 \\
\end{tabular} & 800 & 90 & 90 & 30 & 52 & 20 & 50 & \begin{tabular}{l|l}
50 \\
\end{tabular} & \begin{tabular}{l|l}
50 \\
\end{tabular} & 20 & 20 & 200 & \begin{tabular}{|l|l}
500 \\
\end{tabular} & \begin{tabular}{|l|l|}
800 \\
\end{tabular} & 90 & 0 & 0 \\
\hline 62 & & 50 & 50 & \begin{tabular}{|l|}
50 \\
\end{tabular} & 50 & 50 & 40 & 500 & \begin{tabular}{|l|}
500 \\
\end{tabular} & \begin{tabular}{|l|l}
800 \\
\end{tabular} & 90 & 90 & 60 & 53 & 35 & \begin{tabular}{l|l}
50 \\
\end{tabular} & $\begin{array}{l}50 \\
50\end{array}$ & \begin{tabular}{l|l}
50 &
\end{tabular} & 0 & 20 & 350 & 50 & 800 & 90 & 0 & 0 \\
\hline 63 & 19 & 20 & 20 & 35 & 35 & 35 & 35 & 200 & 200 & 650 & 45 & 45 & 45 & 54 & 50 & 50 & 50 & \begin{tabular}{l|l}
50 \\
5
\end{tabular} & & 20 & 500 & 500 & \begin{tabular}{|l|l|}
800 \\
\end{tabular} & 90 & 0 & 0 \\
\hline & & & & & & & & & & & & & & 55 & 20 & 20 & 20 & 20 & & 20 & 200 & 200 & \begin{tabular}{|l|}
500 \\
\end{tabular} & 0 & 90 & 0 \\
\hline 74 & 21 & \begin{tabular}{|l|}
35 \\
\end{tabular} & \begin{tabular}{|l|}
35 \\
\end{tabular} & 35 & 35 & \begin{tabular}{|l|}
50 \\
\end{tabular} & 50 & 350 & 350 & 650 & 45 & 90 & 90 & 56 & 35 & 20 & 20 & & & 20 & 350 & 200 & 500 & 0 & 90 & 0 \\
\hline 75 & 22 & 20 & 20 & 20 & 35 & 35 & 35 & 200 & 200 & 500 & 45 & 45 & 45 & 57 & 50 & 20 & 20 & 20 & & 20 & 500 & 200 & \begin{tabular}{|l|}
500 \\
\end{tabular} & 0 & 90 & 0 \\
\hline & & & & & & & & & & & & & & & & & & & & & & & & & & \\
\hline 82 & 23 & 35 & 35 & 35 & 50 & 50 & & 350 & 350 & 650 & 90 & 90 & 90 & 78 & 50 & 35 & 50 & 20 & & 20 & 500 & 350 & 800 & 0 & 90 & 0 \\
\hline 83 & 24 & 20 & 20 & 20 & 20 & 35 & 35 & 200 & 200 & \begin{tabular}{|l|}
500 \\
\end{tabular} & 0 & 45 & 45 & 79 & 20 & 50 & 50 & 20 & & 20 & 200 & 500 & \begin{tabular}{|l|l|}
800 \\
\end{tabular} & 0 & 90 & 0 \\
\hline & & & & & & & & & & & & & & 80 & 35 & 50 & 50 & 20 & & 20 & 350 & 500 & \begin{tabular}{|l|l|}
800 \\
\end{tabular} & 0 & 90 & 0 \\
\hline 90 & 25 & 35 & 35 & 50 & 50 & 50 & 50 & 350 & 350 & 800 & 90 & 90 & 90 & 81 & 50 & 50 & 50 & 20 & & 20 & 500 & 500 & \begin{tabular}{|l|l|}
8000 \\
\end{tabular} & 0 & 90 & 0 \\
\hline & & 30 & 30 & 30 & 30 & 30 & 30 & 300 & 300 & 600 & 30 & 30 & 30 & 82 & 20 & 20 & 20 & 20 & & 50 & 200 & 200 & 500 & 0 & 0 & 90 \\
\hline 91 & 26 & \begin{tabular}{|l|l|}
40 \\
40
\end{tabular} & 40 & \begin{tabular}{|l|}
50 \\
\end{tabular} & \begin{tabular}{|l|l|}
40 \\
5
\end{tabular} & \begin{tabular}{|l|}
50 \\
40
\end{tabular} & 40 & $\frac{300}{400}$ & $\frac{300}{400}$ & $\frac{600}{700}$ & $\frac{30}{60}$ & $\frac{30}{60}$ & $\frac{30}{60}$ & 83 & 35 & 20 & 20 & 20 & 20 & 50 & 350 & 200 & \begin{tabular}{|l|l|}
5000 \\
\end{tabular} & 0 & 0 & 90 \\
\hline & & $\frac{100}{30}$ & & & $\frac{70}{20}$ & \begin{tabular}{|l|l|}
30 \\
\end{tabular} & 20 & $\frac{400}{300}$ & 200 & 600 & 0 & 30 & 0 & 84 & 50 & 20 & 20 & 20 & & 50 & 500 & \begin{tabular}{|l|}
200 \\
\end{tabular} & \begin{tabular}{|l|l|}
500 \\
\end{tabular} & 0 & 0 & 90 \\
\hline $\begin{array}{l}93 \\
44\end{array}$ & 27 & \begin{tabular}{|l|l}
50 \\
40
\end{tabular} & $\frac{20}{20}$ & \begin{tabular}{|l|}
50 \\
\end{tabular} & 20 & \begin{tabular}{|l|}
40 \\
\end{tabular} & 20 & 400 & 200 & 700 & 0 & 60 & 0 & & & & & & & & & & & & & \\
\hline & & & & & & & & & & & & & & 105 & 50 & 35 & 50 & 20 & 20 & 50 & 500 & \begin{tabular}{|l|}
350 \\
\end{tabular} & 800 & 0 & 0 & 90 \\
\hline & & & & \begin{tabular}{|l|l|}
50 \\
\end{tabular} & 20 & 50 & 20 & 500 & 201 & 800 & $\pi$ & 90 & $\pi$ & & 20 & 50 & \begin{tabular}{l|l}
50 \\
\end{tabular} & \begin{tabular}{l|l}
20 &
\end{tabular} & & $\begin{array}{l}50 \\
50\end{array}$ & 200 & 5000 & 800 & 0 & 0 & 90 \\
\hline 102 & 30 & $\frac{50}{50}$ & & \begin{tabular}{|l|l|}
50 \\
50
\end{tabular} & 20 & & 201 & 500 & & & 0 & 90 & 0 & & 35 & 50 & $\begin{array}{l}50 \\
50\end{array}$ & 20 & & $\begin{array}{l}50 \\
50\end{array}$ & 350 & 500 & 800 & 0 & 0 & 90 \\
\hline 103 & 30 & \begin{tabular}{|l}
50 \\
50
\end{tabular} & \begin{tabular}{|l|}
30 \\
40 \\
\end{tabular} & \begin{tabular}{|l|}
50 \\
50
\end{tabular} & \begin{tabular}{|l}
30 \\
40
\end{tabular} & $\frac{50}{50}$ & $\begin{array}{ll}30 \\
40\end{array}$ & $\frac{500}{500}$ & \begin{tabular}{|l|}
340 \\
400 \\
\end{tabular} & \begin{tabular}{|l|}
800 \\
800
\end{tabular} & $\frac{30}{60}$ & $\frac{90}{90}$ & \begin{tabular}{|l|l}
30 \\
60
\end{tabular} & 108 & & & 50 & & & 50 & 500 & \begin{tabular}{|c|}
500 \\
\end{tabular} & \begin{tabular}{|c|}
800 \\
\end{tabular} & 0 & 0 & \begin{tabular}{|c|}
90 \\
\end{tabular} \\
\hline
\end{tabular}

Table 8: Set1 of training data for proposed and known method

\begin{tabular}{|c|c|c|c|c|c|c|c|c|c|c|c|c|c|c|c|c|c|c|}
\hline \multirow{3}{*}{$\begin{array}{l}\text { Testing } \\
\text { points } \\
\\
\mathrm{Pn} \\
\end{array}$} & \multirow{2}{*}{\multicolumn{6}{|c|}{ Effector coordinates }} & \multicolumn{6}{|c|}{ Proposed method (PrM) } & \multicolumn{6}{|c|}{ Known method (KnM) } \\
\hline & & & & & & & \multicolumn{2}{|c|}{ Set 1} & \multicolumn{2}{|c|}{ Set 2} & \multicolumn{2}{|c|}{ Set 3} & \multicolumn{2}{|c|}{ Set 1} & \multicolumn{2}{|c|}{ Set 2} & \multicolumn{2}{|c|}{ Set 3} \\
\hline & \multicolumn{6}{|c|}{$\mathrm{P}_{\mathrm{n}}\left(\mathrm{X}, \mathrm{Y}, \mathrm{Z}, \psi_{\mathrm{i}}, \boldsymbol{,} \varphi\right) \mathrm{n}=1, \ldots, 11$} & \begin{tabular}{|c|} 
Position \\
Error
\end{tabular} & \begin{tabular}{|c|} 
Angular \\
Error
\end{tabular} & $\begin{array}{c}\text { Position } \\
\text { Error } \\
\end{array}$ & $\begin{array}{c}\text { Angular } \\
\text { Error } \\
\end{array}$ & \begin{tabular}{|c|} 
Position \\
Error
\end{tabular} & \begin{tabular}{|c|} 
Angular \\
Error
\end{tabular} & \begin{tabular}{|c|} 
Position \\
Error
\end{tabular} & \begin{tabular}{|c|} 
Angular \\
Error
\end{tabular} & \begin{tabular}{|c|} 
Position \\
Error
\end{tabular} & \begin{tabular}{|c|} 
Angular \\
Error
\end{tabular} & \begin{tabular}{|c|} 
Position \\
Error
\end{tabular} & \begin{tabular}{|c|} 
Angular \\
Error \\
\end{tabular} \\
\hline 0 & 1 & 2 & 3 & 4 & 5 & 6 & 7 & 8 & 9 & 10 & 11 & 12 & 13 & 14 & 15 & 16 & 17 & 18 \\
\hline $\mathrm{n}$ & $\mathrm{x}$ & $\mathrm{Y}$ & $\mathrm{z}$ & $\psi$ & $\theta$ & $\varphi$ & 0.0833 & 0.0000 & 0.0015 & 0.0000 & 0.0418 & 0.0000 & 1.4620 & 0.0000 & 0.1597 & 0.0000 & 0.0000 & 0.0000 \\
\hline 1 & 210 & 210 & 510 & 0 & 0 & 0 & 0.2298 & 0.0020 & 0.0093 & 0.0002 & 0.0795 & 0.0028 & \begin{tabular}{|l|}
18.6663 \\
\end{tabular} & 0.1243 & 6.0701 & 0.1582 & 0.0914 & 0.2883 \\
\hline 2 & 230 & 230 & 530 & 0 & 0 & 6.4 & 0.3284 & 0.0023 & 0.0102 & 0.0007 & 0.0774 & 0.0060 & \begin{tabular}{|l|}
31.9270 \\
\end{tabular} & 0.4877 & 8.5636 & 0.5283 & 0.0831 & 1.1327 \\
\hline 3 & 250 & 250 & 550 & 0 & 0 & 12.88 & 0.4247 & 0.0017 & 0.0105 & 0.0009 & 0.0426 & 0.0039 & 39.0282 & 1.0491 & 7.7047 & 0.9262 & 0.0408 & 2.4159 \\
\hline 4 & 270 & 270 & 570 & 0 & 0 & 19.32 & \begin{tabular}{l|l}
0.5645 \\
\end{tabular} & 0.0038 & $\begin{array}{ll}0.0144 \\
\end{array}$ & 0.0009 & 0.0316 & 0.0047 & \begin{tabular}{|l|}
39.9710 \\
\end{tabular} & 1.7607 & 5.9324 & 1.1810 & \begin{tabular}{l|l}
0.0143 \\
\end{tabular} & 3.8805 \\
\hline 5 & 290 & 290 & 590 & 0 & 0 & 25.76 & 0.7743 & 0.0118 & 0.0203 & 0.0010 & 0.0783 & 0.0125 & 35.3201 & 2.5621 & 9.6531 & 1.1573 & 0.0076 & 4.8799 \\
\hline 6 & 310 & 310 & 610 & 0 & 0 & 32.2 & 1.0592 & 0.0265 & 0.0291 & 0.0014 & 0.0917 & 0.0083 & 26.4539 & 3.3790 & 17.6429 & 0.7891 & 0.0145 & 4.0579 \\
\hline 7 & 330 & 330 & 630 & 0 & 0 & 38.64 & 1.4172 & 0.0459 & 0.0471 & 0.0029 & 0.0674 & 0.0115 & 15.9495 & 4.1216 & 26.2353 & 0.1009 & 0.0428 & 0.0715 \\
\hline 8 & 350 & 350 & 650 & 0 & 0 & 45.08 & 1.8491 & 0.0650 & 0.0808 & 0.0060 & $\begin{array}{ll}0.0424 \\
\end{array}$ & 0.0425 & 10.3252 & 4.6882 & \begin{tabular}{|l|l|}
33.4875 \\
\end{tabular} & 0.7905 & 0.0621 & $\begin{array}{ll}6.4541 \\
\end{array}$ \\
\hline 9 & 370 & 370 & 670 & 0 & 0 & 51.52 & 2.3479 & $\begin{array}{ll}0.07699 \\
\end{array}$ & \begin{tabular}{|l|l|}
0.1337 \\
\end{tabular} & 0.0116 & \begin{tabular}{|c|c|}
0.0767 \\
\end{tabular} & \begin{tabular}{|c|}
0.0759 \\
\end{tabular} & \begin{tabular}{|l|}
15.6619 \\
\end{tabular} & 4.9747 & 38.0005 & 1.6983 & 0.0619 & 11.3875 \\
\hline 10 & 390 & 390 & 690 & 0 & 0 & 57.96 & 2.8678 & 0.0746 & \begin{tabular}{|l|l|}
0.2087 \\
\end{tabular} & 0.0201 & \begin{tabular}{|l|l|}
0.1089 \\
\end{tabular} & $\begin{array}{l}0.1033 \\
\end{array}$ & \begin{tabular}{|l|}
22.0037 \\
\end{tabular} & 4.8883 & 38.8002 & 2.4044 & \begin{tabular}{|l|l}
0.0427 \\
\end{tabular} & 12.9225 \\
\hline 11 & 410 & 410 & 710 & 0 & 0 & 64.4 & 3.3076 & 0.0545 & 0.3082 & 0.0322 & 0.1113 & 0.1215 & 24.4418 & 4.3602 & 35.3529 & 2.7036 & 0.0168 & \begin{tabular}{|l|}
11.6250 \\
\end{tabular} \\
\hline 12 & 430 & 430 & 730 & 0 & 0 & $\begin{array}{ll}70.84 \\
\end{array}$ & 3.5670 & 0.0221 & 0.4345 & 0.0482 & 0.0981 & \begin{tabular}{|c|c|}
0.1319 \\
\end{tabular} & \begin{tabular}{|l|}
21.6759 \\
\end{tabular} & 3.3542 & 27.5287 & 2.4402 & 0.0170 & \begin{tabular}{|l|l|}
8.5784 \\
\end{tabular} \\
\hline 13 & 450 & 450 & 750 & 0 & 0 & 77.28 & 3.6831 & 0.0015 & 0.5897 & 0.0682 & 0.1296 & 0.1390 & \begin{tabular}{|l|}
13.4760 \\
\end{tabular} & 1.8705 & 15.5068 & 1.5280 & 0.0197 & 4.5242 \\
\hline 14 & 470 & 470 & 770 & 0 & 0 & 83.72 & 3.8700 & $\begin{array}{ll}0.0394 \\
\end{array}$ & 0.7739 & 0.0919 & \begin{tabular}{|l|l|}
0.2424 \\
\end{tabular} & \begin{tabular}{|l|l|}
0.1476 \\
\end{tabular} & 1.4620 & 0.0005 & 0.1648 & 0.0002 & $\begin{array}{ll}0.0404 \\
\end{array}$ & 0.0000 \\
\hline 15 & 490 & 490 & 790 & 0 & 0 & 90 & 0.0000 & 0.0000 & 0.0000 & 0.0000 & 0.0000 & 0.0000 & 0.0000 & 0.0000 & 0.0000 & 0.0000 & 0.0832 & 0.0000 \\
\hline \multirow{2}{*}{\multicolumn{7}{|c|}{ Standard deviation }} & 1.4209 & 0.028563 & 0.2389 & 0.0282 & 0.0543 & 0.058182 & \begin{tabular}{|l|}
12.8225 \\
\end{tabular} & 1.9209 & \begin{tabular}{|l|l|}
14.2201 \\
\end{tabular} & 0.9163 & 0.0292 & 4.5026 \\
\hline & & & & & & & 3.8700 & 0.076854 & 0.7739 & 0.0919 & 0.2424 & 0.147576 & \begin{tabular}{|l|}
39.9710 \\
\end{tabular} & 4.9747 & \begin{tabular}{|l|l|}
38.80002 \\
\end{tabular} & 2.7036 & 0.0914 & \begin{tabular}{|l|}
12.9225 \\
\end{tabular} \\
\hline
\end{tabular}

Table 9: Simulated results 
positioning and angular errors (represented in the graph as Pos. Er. and Ang. Er.) resulted from the simulation of the move between points $P_{1}$ and $P_{2}$. The results simulated with each neural model (Set 1, Set 2, Set 3) of each method has been marked graphically with PrM for the proposed method and KnM, for the known method.

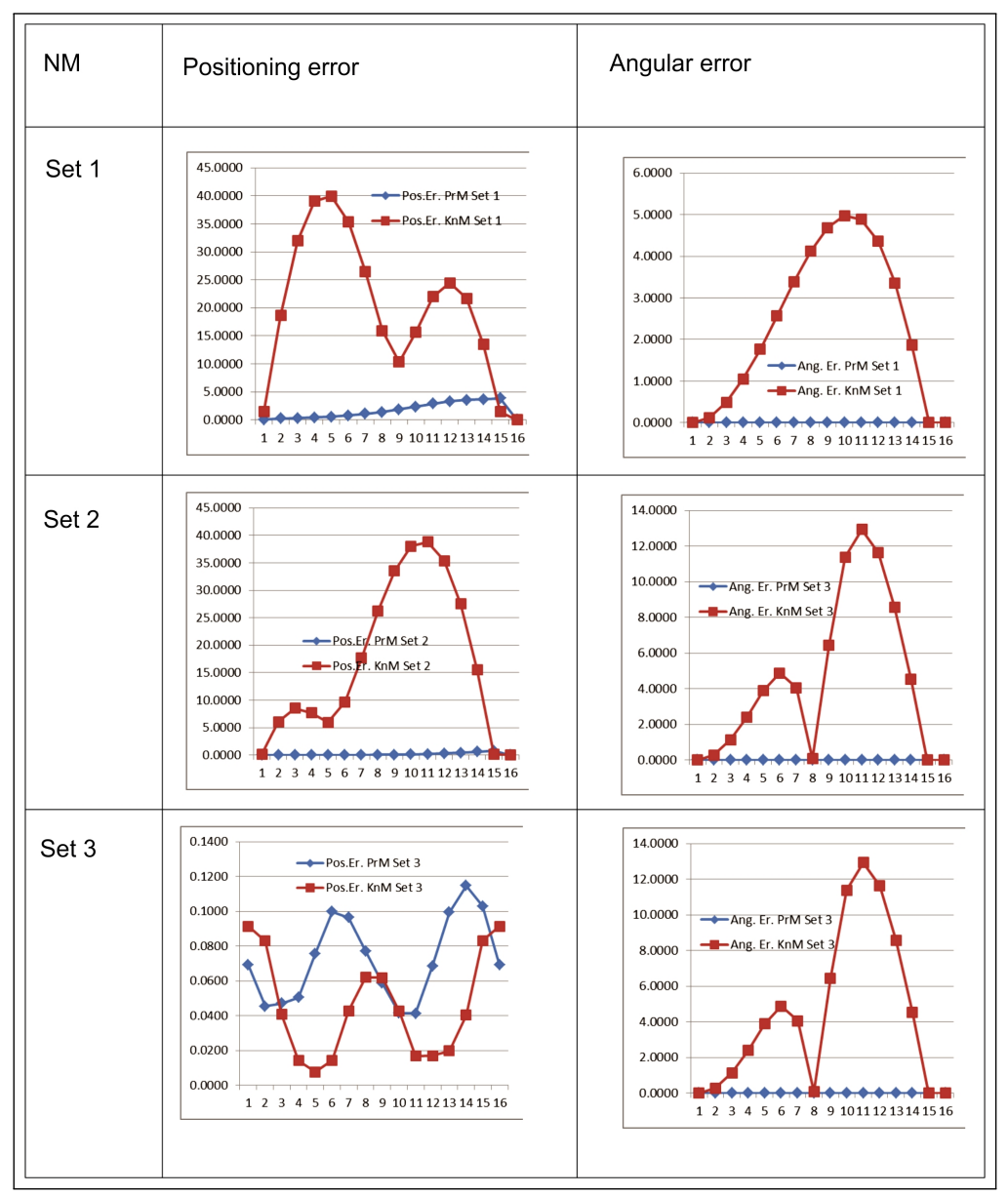

Table 10: Graphical representation of the errors resulted when simulating

\section{Conclusions}

The analysis of the results in Tables 9 and 10 in terms of positioning, angular and cumulated errors demonstrates the following:

- When simulating the move in a straight line, all the three neural models obtained based on the proposed method PrM offer much better results than the models obtained based on the KnM.

- The neural model Set 2-PrM offers positioning precision corresponding to some handling applications $(e<1 \mathrm{~mm})$ although the set of training examples is relatively small $(\mathrm{n}=108)$. By contrast, even if for the neural model Set $2-\mathrm{KnM}$ there has been used a relatively more significant number of training examples $(\mathrm{n}=256)$, this gives greater positioning errors $(e<39 \mathrm{~mm})$ which cannot be accepted.

- The neural model Set 3-PrM $(n=448)$ offers a positioning precision corresponding to the majority of the handling applications $(e<0.25 \mathrm{~mm})$. The neural model Set 3-KnM $(\mathrm{n}=448)$ 
offers the best positioning precision $(e<0.1 \mathrm{~mm})$, but it does not solve the orientation problem, the angular error being greater than 100 .

It has been noted that the neural models generated by the proposed method offer better results as compared to the method of evenly distributed training data in the robot's workspace. The authors find that the proposed method offers superior results, and that it can be used in order to obtain high-quality neural results, with a reduced number of training data.

\section{Bibliography}

[1] Campean E.; Itul T.P.; Tanase I.; Pisla A.; Workspace Generation for a 2 - DOF Parallel Mechanism Using Neural Networks, Applied Mechanics and Materials, Vol 162 (2012), pp 121-130, doi: 10.4028/www.scientific.net/AMM.162.121.

[2] Ciupan E.; Lungu F.; Ciupan C. (2014); A Method for Training a Neural Network with a Small Number of Examples Used for Robot Control, ICCCC 2014, 5th International Conference on Computers Communications \& Control, Romania, Oradea, May 6-10.

[3] Dumitrache, I. (2008); From Model-Based Strategies to Intelligent Control Systems, Proc. of 9th WSEAS International Conference on Automation and Information, 408-415.

[4] Feng Y.; Wanh Y.; Yang Y. (2012); Inverse Kinematics Solution for Robot Manipulator based on Neural Network under Joint Subspace, International Journal of Computers Communications \& Control, 7(3):459-472.

[5] Koker R. (2013); A genetic algorithm approach to a neural-network-based inverse kinematics solution of robotic manipulators based on error minimization, Information Sciences, 222, $528-543$.

[6] Lewis F. L.; Jagannathan S.; Yesildirak A. (1998); Neural network control for robots manipulators and nonlinear systems, Tylor \& Francis.

[7] Negrean I.; Vuscan I.; Haiduc N. (1998); Kinematic and Dynamic Modelling, Editura Didactica si Pedagogica, Bucuresti, ISBN 973-30-5958-7.

[8] Zilouchian A.; Jamshidi M. (2001); Intelligent Control Systems using Soft Computing Methodologies, CRC Press LLC, ISBN 0-8493-1875-0. 